\title{
Physiological responses and proteomic changes reveal insights into Stylosanthes response to manganese toxicity
}

Pandao Liu', Rui Huang ${ }^{1}$, Xuan Hu¹, Yidan Jia ${ }^{1,2}$, Jifu Li ${ }^{1,2}$, Jiajia Luo ${ }^{1,2}$, Qin Liu², Lijuan Luo², Guodao Liu and Zhijian Chen ${ }^{1,2^{*}}$ (D)

\begin{abstract}
Background: Manganese (Mn), an essential element for plants, can be toxic when present in excess. Stylo (Stylosanthes) is a pioneer tropical legume with great potential for Mn tolerance, but its Mn tolerance mechanisms remain poorly understood.

Results: In this study, variations in Mn tolerance were observed among nine stylo genotypes. Stylo genotype 'RY5' exhibited the highest Mn tolerance compared to the other tested genotypes, whereas 'TF2001' was a Mn-sensitive genotype. The mechanisms underlying the response of stylo to Mn toxicity were further investigated using these two genotypes with contrasting Mn tolerance. Results showed that stylo genotype RY5 exhibited Mn tolerance superior to that of genotype TF2001, showing lower reductions in leaf chlorophyll concentration, chlorophyll fluorescence parameters, photosynthetic indexes and plant dry weight under Mn toxicity. A label-free quantitative proteomic analysis was conducted to investigate the protein profiles in the leaves and roots of RY5 in response to Mn toxicity. A total of 356 differentially expressed proteins (DEPs) were identified, including 206 proteins from leaves and 150 proteins from roots, which consisted of 71 upregulated, 62 downregulated, 127 strongly induced and 96 completely suppressed proteins. These DEPs were mainly involved in defense response, photosynthesis, carbon fixation, metabolism, cell wall modulation and signaling. The qRT-PCR analysis verified that 10 out of 12 corresponding gene transcription patterns correlated with their encoding proteins after $\mathrm{Mn}$ exposure. Finally, a schematic was constructed to reveal insights into the molecular processes in the leaves and roots of stylo in response to Mn toxicity.
\end{abstract}

Conclusions: These findings suggest that stylo plants may cope with Mn toxicity by enhancing their defense response and phenylpropanoid pathways, adjusting photosynthesis and metabolic processes, and modulating protein synthesis and turnover. This study provides a platform for the future study of Mn tolerance mechanisms in stylo and may lead to a better understanding of the potential mechanisms underlying tropical legume adaptation to Mn toxicity.

Keywords: Manganese toxicity, Oxidative stress, Antioxidant protection, Proteomics, Stylosanthes

\footnotetext{
* Correspondence: jchen@scau.edu.cn

${ }^{1}$ Institute of Tropical Crop Genetic Resources, Chinese Academy of Tropical

Agricultural Sciences, Haikou 571101, China

${ }^{2}$ Institute of Tropical Agriculture and Forestry, Hainan University, Haikou

570110, China
}

(C) The Author(s). 2019 Open Access This article is distributed under the terms of the Creative Commons Attribution 4.0 International License (http://creativecommons.org/licenses/by/4.0/), which permits unrestricted use, distribution, and reproduction in any medium, provided you give appropriate credit to the original author(s) and the source, provide a link to the Creative Commons license, and indicate if changes were made. The Creative Commons Public Domain Dedication waiver (http://creativecommons.org/publicdomain/zero/1.0/) applies to the data made available in this article, unless otherwise stated. 


\section{Background}

Manganese $(\mathrm{Mn})$ is the second most abundant transition metal in the Earth's crust and is widely distributed in soils, sediments and water as well as in biological materials. Mn exists in many forms, such as free metal ions and soluble or insoluble metal compounds [1]. The available $\mathrm{Mn}$ in soils ranges from 450 to $4000 \mathrm{mg} \mathrm{kg}^{-1}$ and can easily increase with decreasing soil $\mathrm{pH}$ or under reducing soil conditions [2]. Although $\mathrm{Mn}$ in trace amounts is essential for humans, animals and plants, $\mathrm{Mn}$ is considered a heavy metal; at excessive levels in farmlands, it not only decreases crop productivity and quality but also threatens human health [3]. In humans, the accumulation of $\mathrm{Mn}$ affects the central nervous system, leading to the development of Parkinson-like disorders [4]. In plants, excess Mn toxicity causes adverse impacts at various morphological levels, leading to symptoms such as chlorosis and necrosis, crinkled leaves and brown spots and, ultimately, growth inhibition $[5,6]$.

Several toxic effects of $\mathrm{Mn}$ on plants at the physiological level have been reported, such as generating oxidative stress through the accumulation of reactive oxygen species (ROS) [7, 8], impairing leaf structure and chlorophyll biosynthesis, impeding photosynthesis and respiration [9], inhibiting the activities of several key enzymes and disturbing the absorption and translocation of other mineral elements [10]. For example, overproduction of ROS, including hydrogen peroxide $\left(\mathrm{H}_{2} \mathrm{O}_{2}\right)$, superoxide anion $\left(\mathrm{O}_{2}{ }^{-}\right)$, hydroxyl radical $(. \mathrm{OH})$ and singlet oxygen $\left({ }^{1} \mathrm{O}_{2}\right)$, is one of the main effects of $\mathrm{Mn}$ toxicity, causing lipid peroxidation if these ROS are not adequately scavenged [11]. Furthermore, the net photosynthetic rate (Pn), maximum quantum yield of photosystem II (PSII) $(F \mathrm{v} / F \mathrm{~m})$ and effective quantum yield of PSII (ФPSII) of plants are significantly inhibited by $\mathrm{Mn}$ toxicity $[12,13]$.

To avoid the toxic effects of Mn exposure, plants have developed diverse Mn tolerance mechanisms associated with changes in molecular, biochemical and cellular processes $[5,14]$. Increasing evidence shows that plants typically tolerate excess $\mathrm{Mn}$ through activation of the antioxidant system [11], sequestration of $\mathrm{Mn}$ into inactive subcellular sites [15] and generation of Mn chelates with protein-based, organic and inorganic complexes [16]. Important roles of antioxidant systems in response to Mn toxicity, including antioxidant enzymes and nonenzymatic components, have been suggested in many plants, such as common bean (Phaseolus vulgaris) [7], cowpea (Vigna unguiculata) [17], perennial ryegrass (Lolium perenne) [13] and wheat (Triticum polonicum) [11]. It has been demonstrated that the compartmentalization of $\mathrm{Mn}$ in apoplasts, vacuoles,
Golgi and cell walls plays an important role in $\mathrm{Mn}$ tolerance and homeostasis [17-19]. For example, loss-of-function analyses of metal tolerance protein (MTP) demonstrate the importance of Mn sequestration into vacuoles in Mn tolerance in rice (Oryza sativa) and Arabidopsis [20, 21]. Recently, it has been shown that sequestration of $\mathrm{Mn}$ into Golgi-associated compartments by the function of OsMTP11 is also important for $\mathrm{Mn}$ homeostasis in rice [22]. Additionally, organic acids exuded from the root apex can chelate Mn, thereby alleviating $\mathrm{Mn}$ toxicity via decreasing $\mathrm{Mn}$ uptake by the roots [23-25]. It is generally assumed that Mn-toxicity tolerance varies greatly with plant species, variety or genotype. Therefore, dissecting the mechanisms underlying the plant response to $\mathrm{Mn}$ toxicity can provide valuable information for improving crop cultivars by increasing their adaptation to Mn toxicity.

Stylo (Stylosanthes spp.) is a dominant legume used for livestock nutrition and soil improvement, especially in tropical and subtropical areas where acid soils are widely distributed [26]. It has been reported that $S$. guianensis exhibits higher Mn tolerance than many other legumes, such as Medicago sativa, Trifolium repens, Leucaena leucocephala, Glycine javanica and Phaseolus atropurpureus [27]. Recently, a higher Mn toxicity threshold was observed in stylo than in other reported legumes under Mn toxicity [25]. Furthermore, stylo has aluminum $(\mathrm{Al})$ toxicity tolerance comparable to that of Al-tolerant rice $[28,29]$. Accordingly, stylo has been recognized as a pioneer tropical legume with great potential for metal tolerance. Although great efforts have been made to identify the physiological and molecular mechanisms of $\mathrm{Mn}$ tolerance in stylo, they remain poorly understood, which can be attributed to the lack of genome information and limited resources, such as stylo mutants. Furthermore, few studies have integrated analyses of the physiological responses and proteomic profiles of both leaves and roots of plants under Mn toxicity. These studies have the potential to provide insights into plant responses to Mn toxicity. In this study, the effects of Mn toxicity on the growth performance of nine stylo genotypes were investigated. Subsequently, physiological changes in two stylo genotypes contrasting in Mn tolerance were further analyzed. Differentially protein profiles in the leaves and roots of the Mn-tolerant stylo genotype under $\mathrm{Mn}$ toxicity were explored using a label-free quantitative proteomics approach. The potential mechanisms underlying the response of stylo to $\mathrm{Mn}$ toxicity were considered.

\section{Results}

Variability of Mn tolerance in stylo

In this study, growth performance was first examined among nine S. guianensis genotypes subjected to excess 
Mn. Stylo growth was obviously affected by Mn toxicity but showed variation among different genotypes (Additional file 1). RY5 exhibited highest Mn tolerance compared to the other tested stylo genotypes, as reflected higher SPAD values and plant dry weight under Mn toxicity, whereas TF2001 is a Mn-sensitive genotype (Additional file 1). Subsequently, two stylo genotypes, RY5 and TF2001, contrasting in Mn tolerance, were further used to investigate the response of stylo to Mn toxicity. The results showed that SPAD values in the leaves of RY5 and TF2001 were decreased by 19.7 and $48.9 \%$ in the excess Mn treatment compared to their respective controls (Table 1). The SPAD values in RY5 were higher than those in TF2001 under Mn toxicity (Table 1). Chlorophyll fluorescence parameters were monitored to evaluate the photosynthetic performance. The $F \mathrm{v} / F \mathrm{~m}$, ФPSII, excitation pressure of PSII (1-qL) and electron transport rate (ETR) calculated from ФPSII were declined in the two tested stylo genotypes under excess Mn conditions compared to their respective controls (Table 1). Furthermore, the Pn, intercellular $\mathrm{CO}_{2}$ concentration $(\mathrm{Ci})$ and stomatal conductance $(\mathrm{Gs})$ were decreased in stylo treated with excess Mn (Table 1). Interestingly, the chlorophyll fluorescence parameters and photosynthetic indexes in RY5 were higher than in TF2001 under excess Mn conditions (Table 1).

Excess $\mathrm{Mn}$ resulted in decreased shoot and root growth of TF2001 but not RY5. The shoot and root dry weights of TF2001 were 37.1 and $22.5 \%$ lower under Mn toxicity than those of the controls, respectively (Fig. 1a and b). Significant increases in Mn concentration were observed in both the shoots and roots of the two tested stylo genotypes in the excess $\mathrm{Mn}$ treatment relative to the control treatment. However, under excess Mn conditions, the Mn concentrations in shoots and roots were higher in TF2001 than in RY5 by 17.7 and 56.6\%, respectively (Fig. 1c and d). These results suggest that RY5 is more Mn-tolerant than TF2001.

\section{Changes in $\mathrm{H}_{2} \mathrm{O}_{2}$ and malondialdehyde (MDA) levels in response to $\mathrm{Mn}$ toxicity}

The $\mathrm{H}_{2} \mathrm{O}_{2}$ and MDA concentrations in stylo were examined at two Mn levels. The results showed that the $\mathrm{H}_{2} \mathrm{O}_{2}$ concentrations in the leaves and roots of
TF2001 were increased by 13.6 and $39.3 \%$, respectively, under excess $\mathrm{Mn}$ treatment, while $\mathrm{H}_{2} \mathrm{O}_{2}$ concentrations were only increased by $15.1 \%$ in the roots of RY5 when plants were exposed to Mn toxicity compared to the controls (Fig. 2a and b). Similarly, the MDA concentrations in the two tested stylo genotypes were significantly increased by excess Mn treatment (Fig. 2c and d). MDA concentrations in the leaves and roots of RY5 and TF2001 were $12.3-18.8 \%$ and $25.6-39.0 \%$ increased under excess $\mathrm{Mn}$ treatment, respectively, compared to the controls (Fig. 2c and d). Although increases in the concentrations of $\mathrm{H}_{2} \mathrm{O}_{2}$ and MDA were observed in both stylo genotypes subjected to Mn toxicity, RY5 maintained lower levels of $\mathrm{H}_{2} \mathrm{O}_{2}$ and MDA than TF2001 under Mn toxicity (Fig. 2).

\section{Response of the antioxidant system to Mn toxicity}

Subsequently, the activities of three antioxidant enzymes, superoxide dismutase (SOD), peroxidase (POD) and catalase (CAT), were detected in both the leaves and roots of stylo under different $\mathrm{Mn}$ treatments. The results showed that SOD, POD and CAT activities in the leaves and roots of RY5 were significantly increased by excess Mn treatment, whereas only SOD activity was enhanced by $\mathrm{Mn}$ toxicity in the leaves of TF2001, compared to the respective controls (Fig. 3). The SOD, POD and CAT activities in the leaves of RY5 were increased by 94.0, 91.0 and $34.1 \%$ in the excess $\mathrm{Mn}$ treatment compared to those of their respective controls, and the activities of the three tested enzymes in the roots of RY5 were increased by more than $15.0 \%$ under excess Mn conditions compared to their respective controls (Fig. 3).

Similarly, ascorbate (AsA) and glutathione (GSH) concentrations were increased by excess $\mathrm{Mn}$ treatment in RY5 but not in TF2001 (Fig. 4). Compared to their respective controls, the concentrations of AsA in the leaves and roots of RY5 increased by 68.4 and $21.0 \%$ under Mn toxicity, respectively, while the GSH concentrations in leaves and roots of RY5 increased by 19.2 and $33.8 \%$ at excess Mn levels, respectively (Fig. 4). These results suggest that the Mn-tolerant stylo genotype RY5 responds to $\mathrm{Mn}$ toxicity by enhancing the antioxidant system.

Table 1 Chlorophyll fluorescence parameters and photosynthetic indexes of two stylo genotypes under excess Mn treatment

\begin{tabular}{llllllllll}
\hline Genotypes & $\begin{array}{l}\text { Mn } \\
(\mu \mathrm{M})\end{array}$ & SPAD & FV/Fm & DPSIl & $1-\mathrm{qL}$ & ETR & $\begin{array}{l}\mathrm{Pn} \\
\left(\mu \mathrm{mol} \mathrm{m}^{-2} \mathrm{~s}^{-1}\right)\end{array}$ & $\begin{array}{l}\mathrm{Ci} \\
\left(\mu \mathrm{mol} \mathrm{mol} \mathrm{m}^{-1}\right)\end{array}$ & $\begin{array}{l}\mathrm{Gs} \\
\left(\mathrm{mol} \mathrm{m}^{-2} \mathrm{~s}^{-1}\right)\end{array}$ \\
\hline RY5 & 5 & $35.6 \pm 1.4 \mathrm{a}$ & $0.82 \pm 0.01 \mathrm{a}$ & $0.498 \pm 0.048 \mathrm{a}$ & $0.618 \pm 0.023 \mathrm{a}$ & $209.2 \pm 20.2 \mathrm{a}$ & $31.7 \pm 2.0 \mathrm{a}$ & $132.8 \pm 7.5 \mathrm{a}$ & $0.334 \pm 0.013 \mathrm{a}$ \\
& 400 & $28.6 \pm 2.2 \mathrm{~b}$ & $0.66 \pm 0.04 \mathrm{~b}$ & $0.358 \pm 0.045 \mathrm{~b}$ & $0.486 \pm 0.032 \mathrm{~b}$ & $150.4 \pm 19.0 \mathrm{~b}$ & $24.6 \pm 1.5 \mathrm{~b}$ & $114.9 \pm 2.5 \mathrm{~b}$ & $0.245 \pm 0.013 \mathrm{~b}$ \\
& 5 & $34.8 \pm 1.7 \mathrm{a}$ & $0.82 \pm 0.01 \mathrm{a}$ & $0.476 \pm 0.050 \mathrm{a}$ & $0.622 \pm 0.044 \mathrm{a}$ & $199.9 \pm 21.0 \mathrm{a}$ & $32.1 \pm 2.2 \mathrm{a}$ & $130.9 \pm 10.6 \mathrm{a}$ & $0.341 \pm 0.048 \mathrm{a}$ \\
TF2001 & 5 & $17.8 \pm 1.5 \mathrm{c}$ & $0.42 \pm 0.07 \mathrm{c}$ & $0.222 \pm 0.014 \mathrm{c}$ & $0.338 \pm 0.014 \mathrm{c}$ & $93.2 \pm 5.8 \mathrm{c}$ & $15.4 \pm 3.6 \mathrm{c}$ & $104.5 \pm 3.4 \mathrm{~b}$ & $0.161 \pm 0.009 \mathrm{c}$ \\
\hline
\end{tabular}

Four chlorophyll fluorescence parameters, including Fv/Fm, DPSII, 1-qL and ETR, and three photosynthetic indexes, including Pn, Ci and Gs were measured in stylo after $10 \mathrm{~d}$ of 5 or $400 \mu \mathrm{M} \mathrm{MnSO}_{4}$ treatments. Data are means \pm standard errors $(n=4)$. The same letter represents no significant difference at the $P=0.05$ level 


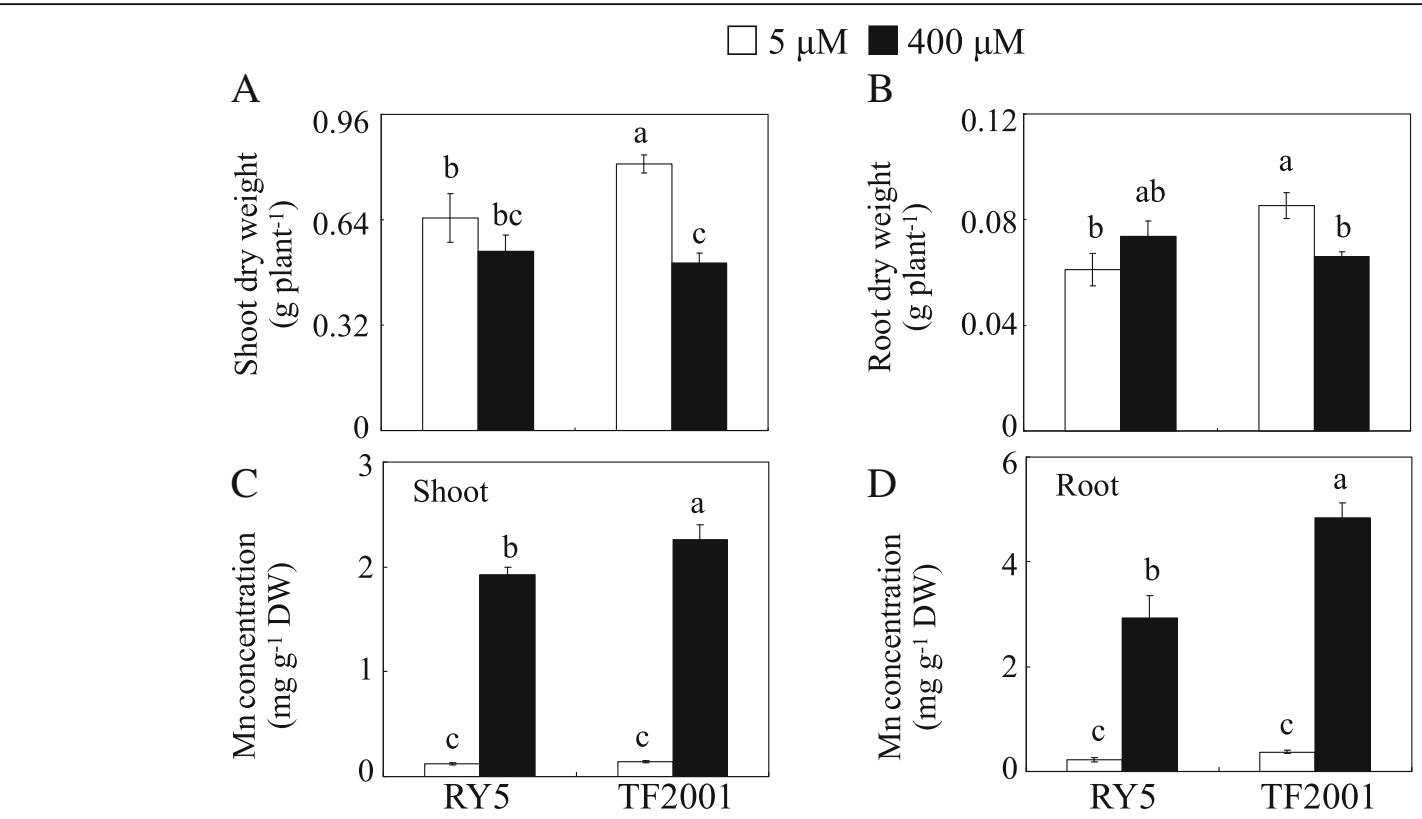

Fig. 1 Effects of the different Mn treatments on stylo growth. (a) Shoot dry weight. (b) Root dry weight. (c) Shoot Mn concentration. (d) Root Mn concentration. After $30 \mathrm{~d}$ of normal growth, stylo seedlings were treated with 5 or $400 \mu \mathrm{M} \mathrm{MnSO}{ }_{4}$ for $10 \mathrm{~d}$. Each bar indicates the mean of four biological replicates with standard error. The same letter represents no significant difference at the $P=0.05$ level

\section{Identification of differentially expressed proteins regulated by $\mathrm{Mn}$ toxicity in stylo}

To dissect the molecular mechanisms underlying the response of stylo to Mn toxicity, a label-free proteomic approach was conducted to identify excess-Mn-responsive proteins in the leaves and roots of the Mn-tolerant stylo genotype RY5. A total of 3048 proteins were identified in both the leaves and roots of RY5 in the two Mn treatments, including 2623 and 2669 proteins detected from the leaves and roots, respectively, and 2244 proteins

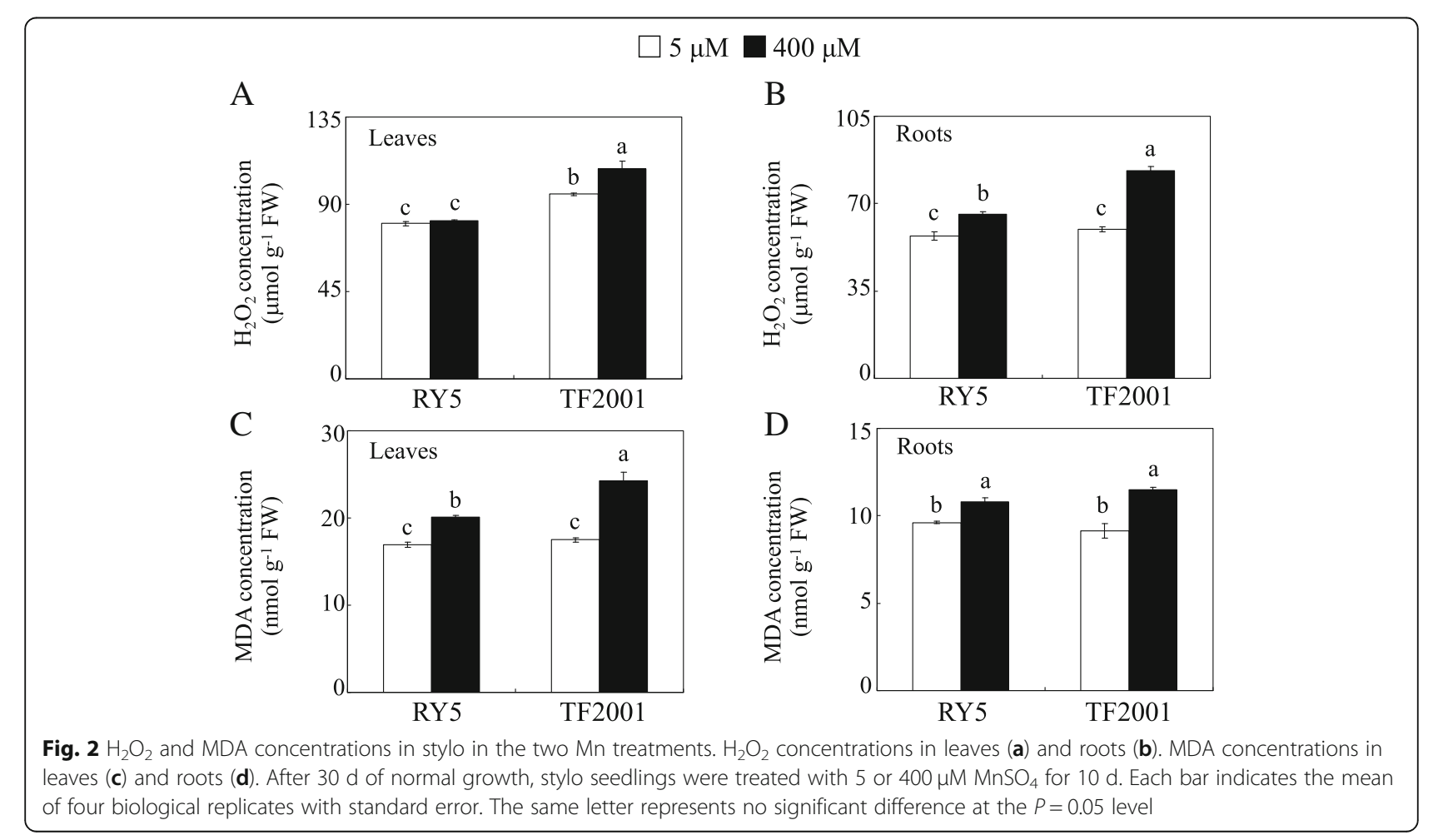




\section{$5 \mu \mathrm{M} \square 400 \mu \mathrm{M}$}

A

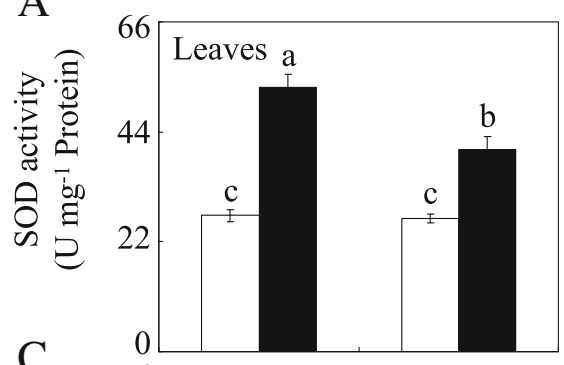

$\mathrm{C}$
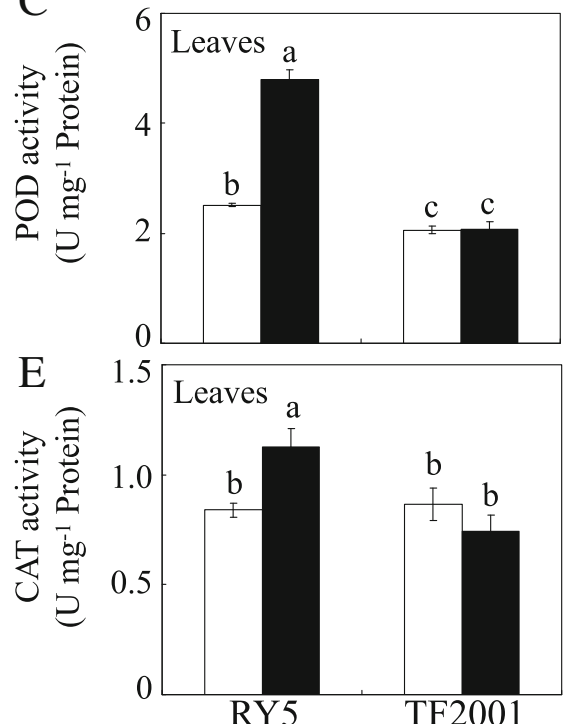

$\mathrm{B}$

$\mathrm{D}$
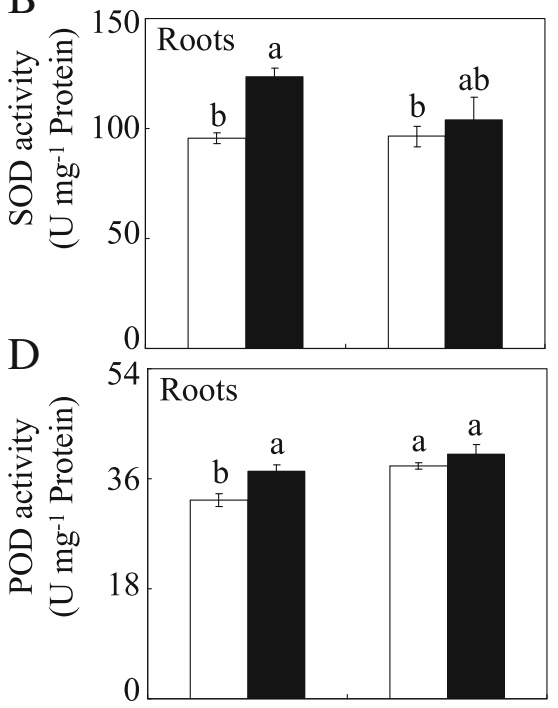

$\mathrm{F}$

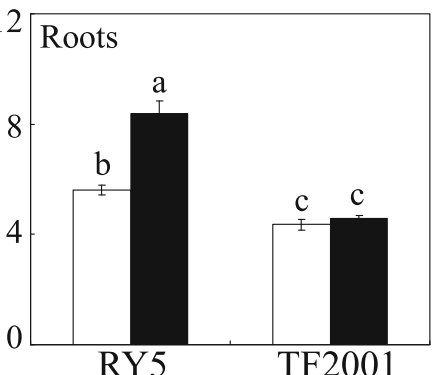

Fig. 3 Analysis of antioxidant enzyme activities. SOD activity in leaves (a) and roots (b). POD activity in leaves (c) and roots (d). CAT activity in leaves (e) and roots (f). After $30 \mathrm{~d}$ of normal growth, stylo seedlings were treated with 5 or $400 \mu \mathrm{M} \mathrm{MnSO} 4$ for $10 \mathrm{~d}$. Each bar indicates the mean of four biological replicates with standard error. The same letter represents no significant difference at the $P=0.05$ level

(73.6\% of the total) overlapped between the leaves and roots (Additional file 2). Proteins with significant changes $(P$ value $<0.05)$ in abundance and abundance changes greater than 2-fold were defined as differentially expressed proteins (DEPs) regulated by excess Mn. In total, 356 proteins exhibited differential expression under the two Mn levels, including 206 proteins from the leaves and 150 proteins from the roots. These DEPs consisted of 71 upregulated, 62 downregulated, 127 strongly induced and 96 completely suppressed proteins (Additional file 2). Among these 356 DEPs, 195 proteins ( $54.8 \%$ of the total) were specific to the leaves, and 139 proteins $(39.0 \%$ of the total) were unique to the roots, while 11 proteins $(3.1 \%$ of the total) overlapped in the leaves and roots (Additional file 2). Detailed information on the fold changes and annotations of the DEPs from the leaves and roots is summarized in Additional file 3.

\section{Functional cataloging of Mn-responsive proteins}

To further investigate the proteomic changes of stylo in response to $\mathrm{Mn}$ toxicity, functional categories, including biological process (BP), molecular function (MF) and cellular component $(\mathrm{CC})$, were determined according to the Gene Ontology (GO) database (Fig. 5). Because some of the DEPs were identified in multiple groups, out of the 356 DEPs, 261 proteins were classified into BP, 300 proteins were grouped into $\mathrm{MF}$ and 143 proteins belonged to $\mathrm{CC}$ (Fig. 5). The results showed that the functional classifications of the 356 DEPs were similar between leaves and roots. Among them, the dominant categories in BP included metabolic process, cellular process and single-organism process terms; the main MF categories were catalytic activity and binding terms; and the prominent categories in CC were cell, cell part and membrane terms (Fig. 5). Subsequently, functional classification of the DEPs was performed according to KEGG analysis. The results showed that the main KEGG pathways in leaves were carbon metabolism, protein processing in endoplasmic reticulum, phenylpropanoid biosynthesis, biosynthesis of amino acids, photosynthesis and starch and sucrose metabolism (Fig. 6a). In roots, the dominant KEGG pathways were carbon metabolism, 
$\square 5 \mu \mathrm{M} \square 400 \mu \mathrm{M}$

A

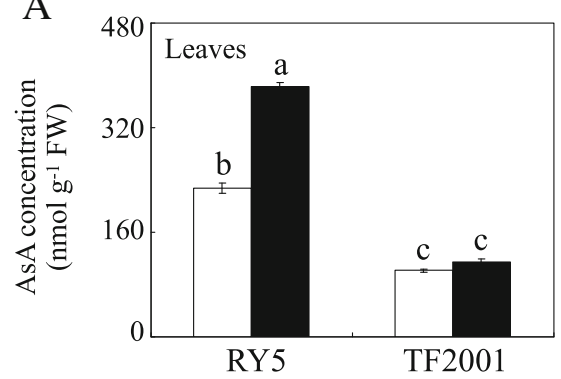

C

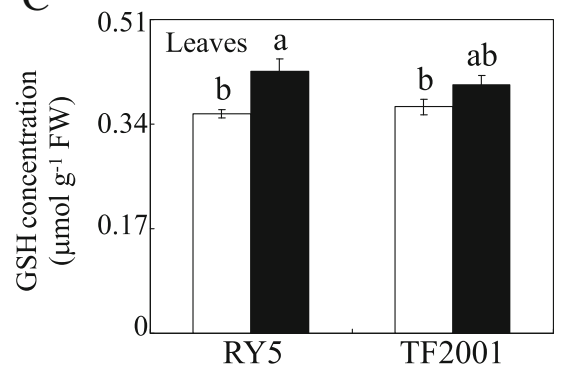

B

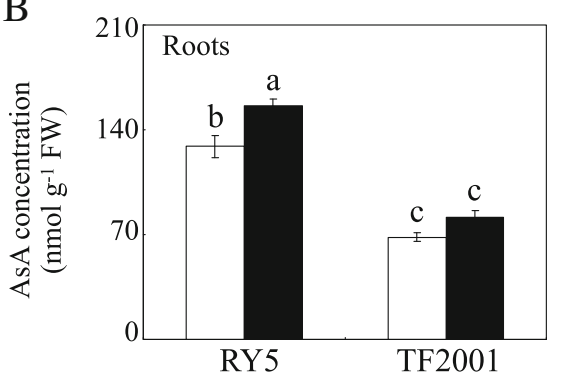

$\mathrm{D}$

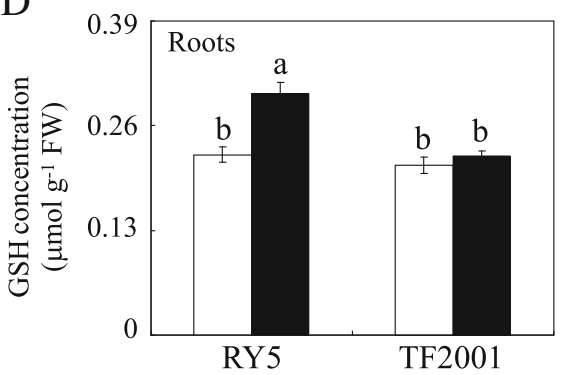

Fig. $4 \mathrm{AsA}$ and GSH concentrations in stylo in the two Mn treatments. AsA concentrations in leaves (a) and roots (b). GSH concentrations in leaves $(\mathbf{c})$ and roots $(\mathbf{d})$. Stylo seedlings were grown under normal conditions for $30 \mathrm{~d}$ and then treated with $5 \mathrm{or} 400 \mathrm{\mu M} \mathrm{MnSO}_{4}$ for $10 \mathrm{~d}$. Each bar indicates the mean of four independent replicates with standard error. The same letter represents no significant difference at the $P=0.05$ level

biosynthesis of amino acids and phenylpropanoid biosynthesis (Fig. 6b).

\section{Expression profiles of DEPs involved in the response of stylo to Mn toxicity}

To detect the expression profiles of proteins involved in the response of stylo to Mn toxicity, candidate DEPs were selected and further separated into different functional groups, such as photosynthesis, carbon metabolism, TCA cycle, defense response, phenylpropanoid biosynthesis, protein metabolism, cell wall modulation and signaling (Table 2). The expression profiles of DEPs involved in photorespiration and the Calvin cycle in leaves and roots of stylo were then extracted and mapped to the reference pathways in KEGG. The results showed that rubisco activase (RCA), ribulose bisphosphate carboxylase large chain (rbcL), phosphoglycolate phosphatase (PGLP), and serine hydroxymethyltransferase (SHMT) were downregulated and fructose-bisphosphate aldolase (FBPA1) was induced in stylo leaves under excess Mn (Fig. 7a). In roots, peroxisomal (S)-2-hydroxy-acid oxidase (GLO), serine-glyoxylate aminotransferase (SGAT) and FBPA2 were strongly induced by Mn toxicity (Fig. 7a). Furthermore, the expression profiles of DEPs involved in the phenylpropanoid pathway were investigated. In leaves, phenylalanine ammonia-lyase (PAL1) was induced, and chalcone-flavonone isomerase (CFI), isoflavone reductase (IFR3) and isoflavone reductase-like protein (IFRL) were upregulated by Mn toxicity (Fig. 7b). In roots, PAL2 and chalcone synthase (CHS) were induced by Mn toxicity, whereas IFR1, IFR2 and IFRL were downregulated (Fig. 7b).

qRT-PCR analysis of genes encoding the candidate DEPs Subsequently, the expression levels of 12 selected genes encoding the candidate DEPs were further detected using qRT-PCR analysis. As shown in Fig. 8, the transcriptional levels of 10 out of 12 genes in RY5 leaves or roots were consistent with their protein accumulation patterns after Mn exposure. Among them, the expressions of citrate synthase (CS), phosphoenolpyruvate carboxylase (PEPC1), peroxidase (POD1), probable glutathione S-transferase (GST), chalcone synthase (CHS), xyloglucan endotransglucosylase/hydrolase (XTH), ubiquitin-conjugating enzyme (UBC), E3 ubiquitin-protein ligase (UPL1) and 14-3-3 were increased in RY5 leaves or roots with excess Mn treatments, while the expansin $(E x p)$ gene was downregulated in leaves and roots of RY5 under Mn toxicity compared to those of the controls (Fig. 8). However, the transcriptional levels of pathogenesis-related protein 10 (PR10-1) and phenylalanine ammonia-lyase (PAL1) differed from the accumulation patterns of their respective encoding proteins in the RY5 response to Mn treatments (Fig. 8). Furthermore, except for POD1, PR10-1 and 14$3-3$, the transcripts of the other tested genes were not regulated by excess Mn in leaves or roots of TF2001 (Fig. 8). 


Metabolic process
Cellular process
Single-organism process
Biological regulation
Localization
Response to stimulus
Regulation of biological process
Cellular component organization
Negative regulation of biological process
Detoxification
Signaling
Catalytic activity
Binding
Antioxidant activity
Structural molecule activity
Electron carrier activity
Transporter activity
Molecular transducer activity
Signal transducer activity
Molecular function regulator
Nutrient reservoir activity
Cell
Cell part
Membrane
Organelle
Macromolecular complex
Membrane part
Organelle part
Extracellular region
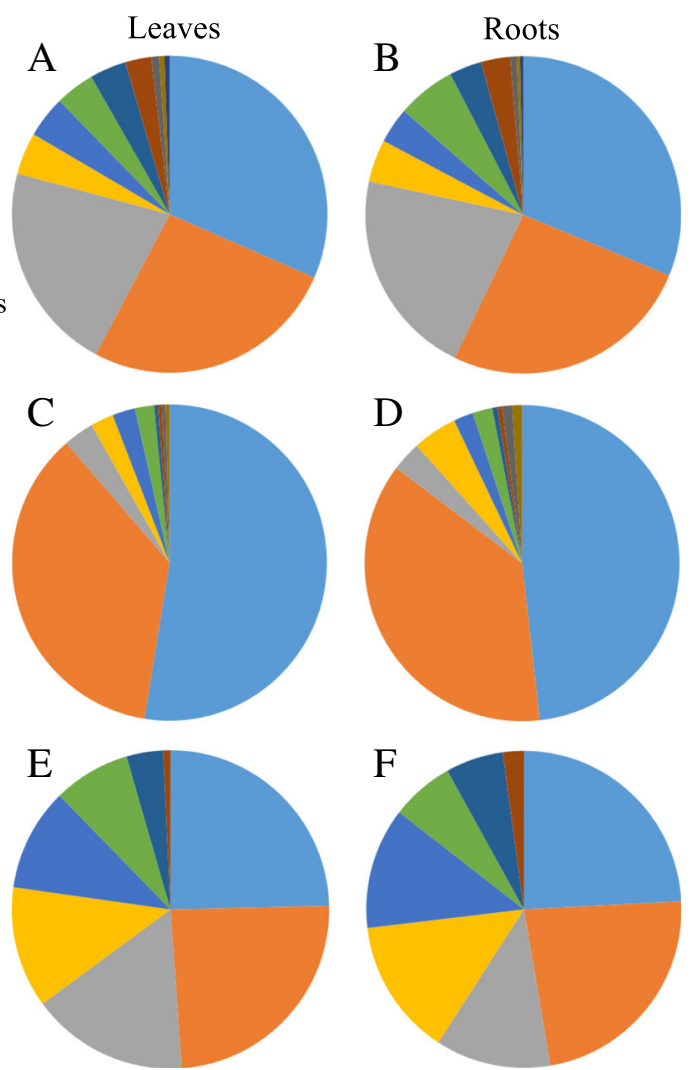

Fig. 5 Gene ontology (GO) analysis of DEPs in stylo. DEPs in leaves $(\mathbf{a}, \mathbf{c}, \mathbf{e})$ and roots $(\mathbf{b}, \mathbf{d}$, $\mathbf{f})$ were classified into three groups: biological process $(\mathbf{a}, \mathbf{b})$, molecular function $(\mathbf{c}, \mathbf{d})$ and cellular component $(\mathbf{e}, \mathbf{f})$

\section{Discussion}

\section{RY5 has superior Mn tolerance}

Mn toxicity disrupts various biological processes in plants, such as inhibiting chlorophyll biosynthesis and photosynthesis, which decreases plant yield [11, 13]. Plants originating from tropical and subtropical areas are assumed to have great potential to tolerate metal toxicity, such as $\mathrm{Al}$ and $\mathrm{Mn}$ toxicity [25, 29, 30]. In accordance with this hypothesis, among 12 different legume plants, stylo, a tropical legume, exhibits high Mn tolerance [27]. However, the physiological and molecular mechanisms underlying the response of stylo to $\mathrm{Mn}$ toxicity are poorly understood. In this study, variations in Mn tolerance were observed among nine stylo genotypes (Additional file 1). RY5, a Mn-tolerant genotype, and TF2001, a Mn-sensitive stylo genotype, were further selected to dissect $\mathrm{Mn}$ toxicity/tolerance mechanisms. The results showed that when grown at $400 \mu \mathrm{M} \mathrm{Mn}$, the stylo genotype RY5 exhibited higher Mn tolerance than the genotype TF2001, as reflected by the smaller reduction in leaf chlorophyll concentration, chlorophyll fluorescence parameters, photosynthetic indexes and the maintenance of RY5 plant dry weight (Table 1 and Fig. 1). Similar results have been found in perennial ryegrass; the plant dry weight, chlorophyll concentration and photosynthesis declined to a greater extent in the Mn-sensitive cultivar Nui than in the Mn-tolerant cultivar Kingston under Mn toxicity [13]. Furthermore, although the Mn concentrations in the shoots and roots were significantly increased in both stylo genotypes subjected to $\mathrm{Mn}$ toxicity, the Mn levels in the shoots and roots were lower in RY5 than in TF2001 under excess Mn treatment (Fig. 1). This result suggests that the regulation of $\mathrm{Mn}$ uptake and transport might be a strategy for adapting to $\mathrm{Mn}$ toxicity. Similarly, regulation of $\mathrm{Mn}$ homeostasis has also been reported in the rice response to Mn toxicity [31].

Although excess-Mn-regulated DEPs have been previously reported in different plant species, such as cowpea [17], soybean [32], Citrus [33], rice and barley [34], this study identified many additional Mn-regulated DEPs using a label-free proteomic approach. Furthermore, the candidate DEPs in the response of stylo to Mn toxicity were integrated into specific pathways, and a schematic was constructed to display the molecular processes in the leaves and roots of stylo in response to Mn toxicity (Fig. 9 and Table 2). 


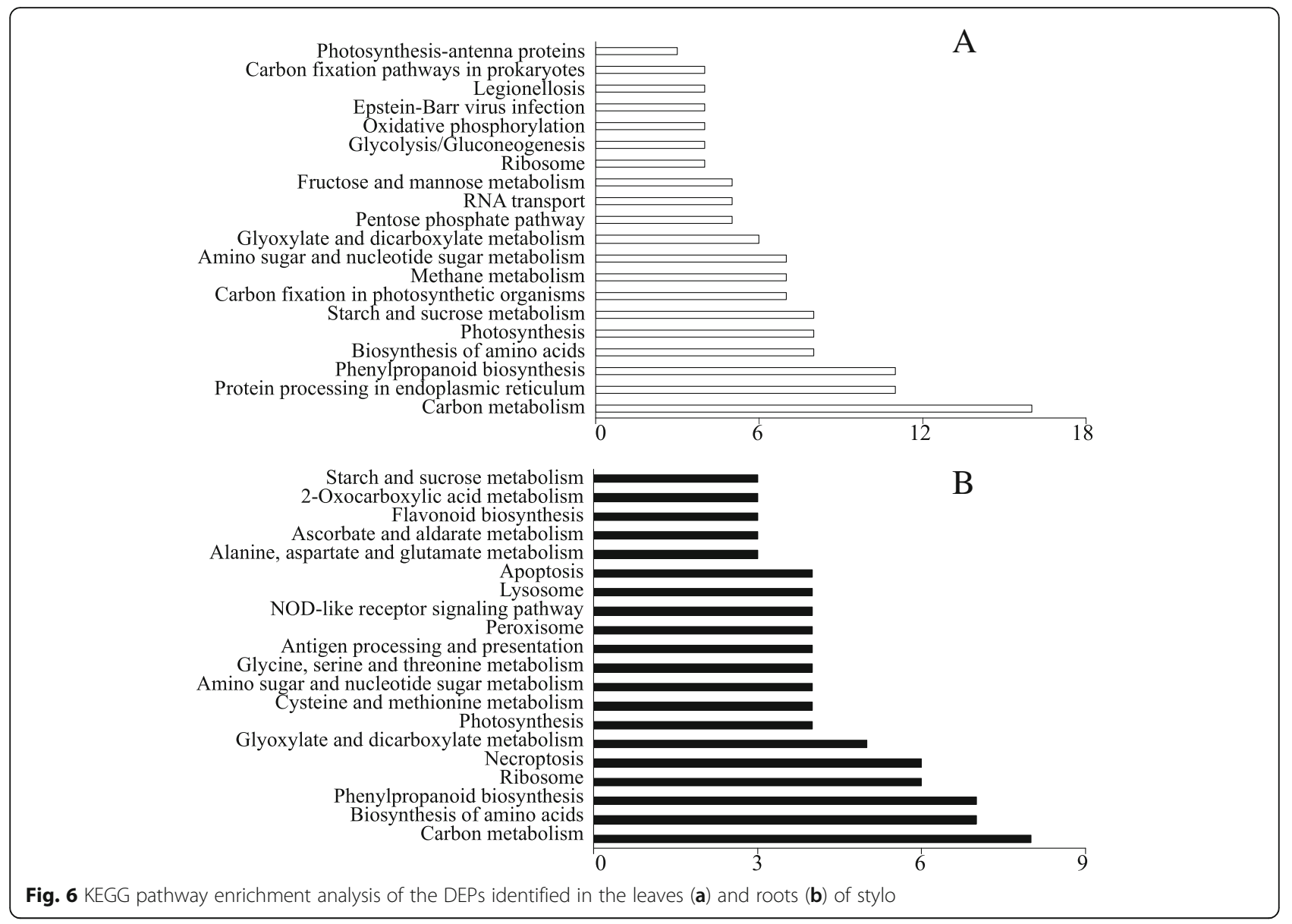

\section{Photosynthesis modulation under Mn toxicity}

Mn toxicity-caused inhibition of plant growth is closely related to the reduction of photosynthesis $[12,35,36]$. Under excess Mn condition, the photosynthesis of stylo was significantly inhibited, which was reflected by the decline of chlorophyll content, fluorescence parameters (e.g., $F \mathrm{v} / F \mathrm{~m}$, ФPSII, 1-qL and ETR) and photosynthetic indexes (e.g., $\mathrm{Pn}, \mathrm{Ci}$ and Gs), especially in the Mn-sensitive stylo genotype TF2001 (Table 1). Similar phenomenon were also observed in rice [35], Citrus [12], polish wheat [36] and cucumber (Cucumis sativus) [37] exposed to Mn toxicity.

The stability and activity of PSII were probably affected in stylo by Mn toxicity, as reflected by the decline of $F \mathrm{v} / F \mathrm{~m}$, ФPSII and 1-qL and ETR (Table 1), and the decreased abundances of PSII complex proteins, such as PSII CP43 reaction center protein (PsbC), PSII oxygen-evolving enhancer protein (OEE) and chlorophyll a-b binding protein ( $\mathrm{LHCa} / \mathrm{b})$ (Table 2). As $\mathrm{LHCa} / \mathrm{b}$ and PsbC are components of the PSII complex and help catalyze the light-induced photochemical processes of PSII [38], the decrease in the abundance of $\mathrm{LHCa} / \mathrm{b}$ and PsbC suggests that the PSII photochemistry activity is modulated in the response of stylo to Mn toxicity.
Furthermore, the decreased abundances of electron transfer flavoprotein subunit (ETFA) and PSI complex proteins, such as PSI P700 chlorophyll a apoprotein A1 (PsaA) and PSI iron-sulfur center (PsaC), would lead to inhibit electron transport process in stylo (Fig. 9 and Table 1). Similarly, decreases in PsaA protein levels have also been observed in Arabidopsis treated with excess $\mathrm{Mn}$ [9]. Besides, the regulation of $\mathrm{LHCa} / \mathrm{b}$ levels is regarded as an adaptive strategy to balance energy distribution between PSII and PSI for redox homeostasis modulation in chloroplasts [39]. Thus, the PSI and PSII complexes are likely the major targets of Mn toxicity in stylo.

In this study, Gs, Ci and Pn significantly declined in stylo under excess Mn condition (Table 1). The declined stomatal conductance probably led to the decreased leaf intercellular $\mathrm{CO}_{2}$ levels and consequently the decreased photosynthesis in stylo. This was supported by subsequent proteomics analysis that decreases in the abundances of photorespiration- and Calvin cycle-related proteins were observed in the leaves of RY5 treated with excess $\mathrm{Mn}$, including rubisco activase (RCA), ribulose bisphosphate carboxylase large chain ( $\mathrm{rbcL}$ ), phosphoglycolate phosphatase (PGLP), and serine 
Table 2 Proteins and their fold changes in the leaves and roots of stylo under Mn toxicity

\begin{tabular}{|c|c|c|c|c|}
\hline \multirow{2}{*}{$\begin{array}{l}\text { Accession } \\
\text { number }\left({ }^{a}\right)\end{array}$} & \multirow[t]{2}{*}{ Protein name $\left({ }^{b}\right)$} & \multirow{2}{*}{$\begin{array}{l}\text { Protein } \\
\text { abbreviation }\end{array}$} & \multicolumn{2}{|l|}{ Fold change } \\
\hline & & & Leaf $(\mathrm{Mn} / \mathrm{CK})$ & $\operatorname{Root}(\mathrm{Mn} / \mathrm{CK})$ \\
\hline \multicolumn{5}{|l|}{ Photosynthesis } \\
\hline I1LC20 & Chlorophyll a-b binding protein & $\mathrm{LHCa} / \mathrm{b}^{1}$ & n.s. & Suppressed \\
\hline A0A151RZX1 & Chlorophyll a-b binding protein & $\mathrm{LHCa} / \mathrm{b}^{2}$ & 0.46 & n.s. \\
\hline A0A1S3TRJ8 & Chlorophyll a-b binding protein & $\mathrm{LHCa} / \mathrm{b}^{3}$ & 0.33 & n.s. \\
\hline A0A1L5BWG5 & Photosystem I P700 chlorophyll a apoprotein A1 & PsaA & 0.46 & n.s. \\
\hline V5JDR5 & Photosystem I iron-sulfur center & PsaC & 0.49 & n.s. \\
\hline D3J8F9 & Photosystem II CP43 reaction center protein & $\mathrm{PsbC}^{1}$ & 0.29 & n.s. \\
\hline R9ZUR7 & Photosystem II CP43 reaction center protein & $\mathrm{PsbC}^{2}$ & Induced & n.s. \\
\hline G7K9H5 & Photosystem II oxygen-evolving enhancer protein & OEE & n.s. & Suppressed \\
\hline A0A1S2XT02 & Photosynthetic NDH subunit of subcomplex B 2 & PNSB2 & Suppressed & n.s. \\
\hline A0A1S2YJBO & Electron transfer flavoprotein subunit alpha & ETFA & Suppressed & n.s. \\
\hline Q9LKH8 & NADPH-protochlorophyllide oxidoreductase & Por & n.s. & Suppressed \\
\hline AOA0B2QNMO & $\begin{array}{l}\text { ATP-dependent Clp protease ATP-binding } \\
\text { subunit clpA like CD4B }\end{array}$ & $\mathrm{CD} 4 \mathrm{~B}$ & n.s. & Suppressed \\
\hline V7BKQ7 & Cytochrome c oxidase subunit $5 \mathrm{C}$ & $\operatorname{cox} 5 \mathrm{C}$ & 2.34 & n.s. \\
\hline E3NYU2 & Rubisco activase 2 & RCA & 0.30 & n.s. \\
\hline E0D980 & Ribulose bisphosphate carboxylase large chain & $\mathrm{rbcL}$ & 0.28 & n.s. \\
\hline AOAOROFCD1 & Phosphoglycolate phosphatase & PGLP & 0.50 & n.s. \\
\hline A0A072V9Z1 & Peroxisomal (S)-2-hydroxy-acid oxidase GLO1 & GLO & n.s. & Induced \\
\hline A0A1J7GY35 & Serine hydroxymethyltransferase & SHMT & 0.42 & n.s. \\
\hline A0A151T118 & Serine-glyoxylate aminotransferase & SGAT & n.s. & Induced \\
\hline \multicolumn{5}{|l|}{ TCA cycle } \\
\hline A0A0B2S2G8 & Citrate synthase & CS & n.s. & 2.04 \\
\hline A0A1S3VRHO & Succinate dehydrogenase & $\mathrm{SDH}$ & Induced & n.s. \\
\hline G7JYQ8 & Aconitate hydratase & $A H^{1}$ & Induced & n.s. \\
\hline A0A1S2Z8R6 & Aconitate hydratase & $A H^{2}$ & n.s. & 0.47 \\
\hline \multicolumn{5}{|l|}{ Carbon fixation } \\
\hline C9W980 & Phosphoenolpyruvate carboxylase & $\mathrm{PEPC}^{1}$ & 2.58 & n.s. \\
\hline BOLXE5 & Phosphoenolpyruvate carboxylase & PEPC $^{2}$ & 2.75 & n.s. \\
\hline Q8H946 & Phosphoenolpyruvate carboxylase & PEPC $^{3}$ & 3.80 & n.s. \\
\hline Q8W4X0 & Cytosolic malate dehydrogenase & $\mathrm{MDH}$ & Suppressed & n.s. \\
\hline A0A0L9VHL1 & Malic enzyme & ME & n.s. & Suppressed \\
\hline \multicolumn{5}{|l|}{ Glycolysis } \\
\hline 11M6D5 & Fructose-bisphosphate aldolase & $\mathrm{FBPA}^{1}$ & n.s. & Induced \\
\hline I3SUU7 & Fructose-bisphosphate aldolase & $\mathrm{FBPA}^{2}$ & Induced & n.s. \\
\hline V7C1L3 & Glucose-6-phosphate isomerase & G6PI & Suppressed & n.s. \\
\hline \multicolumn{5}{|c|}{ Amino acid metabolism } \\
\hline O04998 & Glutamine synthetase & GLN & 2.49 & n.s. \\
\hline A0A1S3VJ34 & Glutamate synthase & GLT & n.s. & 0.33 \\
\hline A0A142F3D2 & Glutamate dehydrogenase & GluDH & Induced & n.s. \\
\hline A0A1S3TXT3 & Ornithine carbamoyltransferase & OCT & n.s. & Induced \\
\hline A0A1S3EC55 & S-adenosylmethionine synthase & SAMS & 2.37 & n.s. \\
\hline
\end{tabular}

Other metabolism 
Table 2 Proteins and their fold changes in the leaves and roots of stylo under Mn toxicity (Continued)

\begin{tabular}{|c|c|c|c|c|}
\hline \multirow{2}{*}{$\begin{array}{l}\text { Accession } \\
\text { number }\left({ }^{\mathrm{a}}\right)\end{array}$} & \multirow[t]{2}{*}{ Protein name $\left({ }^{b}\right)$} & \multirow{2}{*}{$\begin{array}{l}\text { Protein } \\
\text { abbreviation }\end{array}$} & \multicolumn{2}{|l|}{ Fold change } \\
\hline & & & Leaf $(\mathrm{Mn} / \mathrm{CK})$ & $\operatorname{Root}(\mathrm{Mn} / \mathrm{CK})$ \\
\hline AOAOB2PML9 & Sucrose synthase 2 & SuSy & Suppressed & n.s. \\
\hline A0A151TQQ3 & Alde 1-epimerase & Aepi & 4.18 & n.s. \\
\hline Q7X9T1 & Alpha-amylase & AMY & Induced & n.s. \\
\hline H6U596 & Alcohol dehydrogenase & $\mathrm{ADH}$ & Induced & n.s. \\
\hline BOFBK6 & Acetolactate synthase & ALS & n.s. & Induced \\
\hline AOAOB2NWN8 & 3-hydroxyisobutyryl-CoA hydrolase-like protein 5 & $3-\mathrm{HCHL}$ & Suppressed & n.s. \\
\hline A0A151R9N4 & Formate dehydrogenase & $\mathrm{FDH}$ & Induced & n.s. \\
\hline \multicolumn{5}{|l|}{ ATP synthase } \\
\hline A0A1J7HQT2 & ATP synthase subunit beta & ATP synthase ${ }^{1}$ & n.s. & Induced \\
\hline AOA1S2YASO & ATP synthase subunit b & ATP synthase ${ }^{2}$ & n.s. & Suppressed \\
\hline A0A072TW18 & F0F1-type ATP synthase & ATP synthase ${ }^{3}$ & Induced & n.s. \\
\hline $\mathrm{AOA} 120 \mid \mathrm{H} 31$ & ATPase subunit 8 & ATPase & Induced & n.s. \\
\hline \multicolumn{5}{|c|}{ Defense response } \\
\hline A0A1J7HRM7 & Peroxidase & $\mathrm{POD}^{1}$ & 2.95 & n.s. \\
\hline P22195 & Cationic peroxidase 1 & $\mathrm{POD}^{2}$ & 2.18 & n.s. \\
\hline A0A072UXA0 & Peroxidase & $\mathrm{POD}^{3}$ & Induced & n.s. \\
\hline AOAOB2SWWO & Peroxidase & $\mathrm{POD}^{4}$ & Induced & n.s. \\
\hline A0A1J7G991 & Peroxidase & $\mathrm{POD}^{5}$ & Induced & n.s. \\
\hline A0A151TL42 & Peroxidase & $\mathrm{POD}^{6}$ & Induced & n.s. \\
\hline G7INV1 & Peroxidase & $\mathrm{POD}^{7}$ & Induced & n.s. \\
\hline A0A151R770 & Peroxidase & $\mathrm{POD}^{8}$ & n.s. & 0.45 \\
\hline K7KG78 & Peroxidase & $\mathrm{POD}^{9}$ & n.s. & 2.70 \\
\hline |1L|46 & Peroxidase & $\mathrm{POD}^{10}$ & n.s. & Suppressed \\
\hline A0A1S2Y825 & Peroxidase & $\mathrm{POD}^{11}$ & n.s. & Suppressed \\
\hline A0A1S3T7B9 & Peroxidase & $\mathrm{POD}^{12}$ & n.s. & Suppressed \\
\hline A0A1S2YK26 & Probable glutathione S-transferase & GST & 3.75 & n.s. \\
\hline Q5XXQ4 & Pathogenesis-related protein 10 & PR10 ${ }^{1}$ & n.s. & 2.21 \\
\hline Q6VT83 & Pathogenesis-related protein 10 & PR10 ${ }^{2}$ & n.s. & 0.10 \\
\hline K4LMW7 & Pathogenesis-related protein 10b & PR10b & Induced & n.s. \\
\hline Q7X9F6 & Chitinase class Ib & $\mathrm{CHI}$ & Induced & n.s. \\
\hline A0A151R8U8 & Endochitinase & $\mathrm{ECHI}$ & Induced & n.s. \\
\hline Q9S9H7 & Beta-1,3-glucanase & GLU & n.s. & 0.27 \\
\hline $\mathrm{A} 2 \mathrm{Q} 4 \mathrm{Q} 4$ & Polyphenol oxidase & PPO & 2.33 & n.s. \\
\hline G7K6C8 & NAD(P)H:quinone oxidoreductase & NQOR & Induced & n.s. \\
\hline A0A1S3WW46 & Quinone oxidoreductase-like protein 2 homolog & QOR & Induced & n.s. \\
\hline A0A1S3VNB5 & $\begin{array}{l}\text { Probable NAD(P)H dehydrogenase (Quinone) } \\
\text { FQR1-like } 2\end{array}$ & FQR1L2 & n.s. & Suppressed \\
\hline AOAOKOK9R9 & Universal stress protein & USP & Suppressed & Suppressed \\
\hline G9C018 & Cold dehydrin & CDD & Induced & n.s. \\
\hline A0A151TJU2 & Osmotin-like protein & Osmotin & Induced & 3.46 \\
\hline A0A151T914 & Light-regulated protein & LRP & 0.37 & n.s. \\
\hline A0A151TUS7 & Protein IN2-1 isogeny B & IN2-1 & 2.66 & n.s. \\
\hline
\end{tabular}

Phenylpropanoid pathway 
Table 2 Proteins and their fold changes in the leaves and roots of stylo under Mn toxicity (Continued)

\begin{tabular}{|c|c|c|c|c|}
\hline \multirow{2}{*}{$\begin{array}{l}\text { Accession } \\
\text { number }\left({ }^{a}\right)\end{array}$} & \multirow[t]{2}{*}{ Protein name $\left({ }^{b}\right)$} & \multirow{2}{*}{$\begin{array}{l}\text { Protein } \\
\text { abbreviation }\end{array}$} & \multicolumn{2}{|l|}{ Fold change } \\
\hline & & & Leaf $(\mathrm{Mn} / \mathrm{CK})$ & Root $(\mathrm{Mn} / \mathrm{CK})$ \\
\hline AOPBZ9 & Phenylalanine ammonia-lyase & $\mathrm{PAL}^{1}$ & Induced & n.s. \\
\hline AOAOR4J2S3 & Phenylalanine ammonia-lyase & $\mathrm{PAL}^{2}$ & n.s. & Induced \\
\hline Q01287 & Chalcone synthase 2 & $\mathrm{CHS}$ & n.s. & Induced \\
\hline A0A1S2Y0E4 & Chalcone-flavonone isomerase family protein & CFI & 2.30 & n.s. \\
\hline A0A068JKQ1 & Isoflavone reductase & $\mathrm{IFR}^{1}$ & n.s. & 0.20 \\
\hline A0A151TIC8 & Isoflavone reductase & $\mathrm{IFR}^{2}$ & n.s. & 0.49 \\
\hline P52576 & Isoflavone reductase & $\mathrm{IFR}^{3}$ & 2.71 & n.s. \\
\hline A0A072UCP6 & Isoflavone reductase-like protein & IFRL & 3.67 & 0.43 \\
\hline A0A1S2YI24 & 2-hydroxyisoflavanone synthase-like & IFS & n.s. & Suppressed \\
\hline \multicolumn{5}{|c|}{ Lignin pathway } \\
\hline A0A1J7GGU7 & Dirigent protein & $\mathrm{DIR}^{1}$ & Induced & n.s. \\
\hline A0A151SV45 & Dirigent protein & $\mathrm{DIR}^{2}$ & 2.13 & n.s. \\
\hline A0A0L9VQD6 & Dirigent protein & $\mathrm{DIR}^{3}$ & n.s. & Induced \\
\hline E3NYT4 & Dirigent protein & $\mathrm{DIR}^{4}$ & n.s. & 2.36 \\
\hline \multicolumn{5}{|l|}{ Cytoskeleton } \\
\hline A0A072VQC8 & Tubulin alpha chain & a-tubulin & n.s. & Induced \\
\hline P37392 & Tubulin beta- 1 chain & $\beta$-tubulin & n.s. & Induced \\
\hline \multicolumn{5}{|c|}{ Cell wall modulation } \\
\hline M1PNG4 & Expansin & Exp & Suppressed & n.s. \\
\hline G7IMV1 & Alpha-L-arabinofuranosidase/beta-D-xylosidase & ASD/BXL & n.s. & 3.73 \\
\hline AOAOB2PFS3 & Fasciclin-like arabinogalactan protein 12 & FLA & n.s. & 0.50 \\
\hline A0A151SRS4 & Xyloglucan endotransglucosylase/hydrolase & XTH & n.s. & 2.01 \\
\hline A0A1S3UQ47 & Plasmodesmata callose-binding protein 3 & PDCB & Induced & 2.17 \\
\hline \multicolumn{5}{|l|}{ Transcription } \\
\hline $\mathrm{A} 0 \mathrm{~A} 0 \mathrm{~B} 2 \mathrm{Q} 3 \times 5$ & Histone H1.2 & $\mathrm{H} 1.2$ & n.s. & 2.31 \\
\hline C6TDQ3 & Nuclear pore complex protein NUP35 & NUP35 & Induced & n.s. \\
\hline \multicolumn{5}{|c|}{ RNA processing } \\
\hline A0A151SA18 & Ribonucleases P/MRP protein subunit POP1 & POP1 & n.s. & 5.88 \\
\hline \multicolumn{5}{|c|}{ Protein synthesis } \\
\hline A0A1S2X984 & Elongation factor 1-gamma & EF1g & Induced & Induced \\
\hline A0A072VFI9 & Elongation factor 1-alpha & EF1a & Suppressed & n.s. \\
\hline V7ATK1 & Eukaryotic translation initiation factor 3 subunit B & eTIF3b & Induced & n.s. \\
\hline A0A1J7G0E8 & Eukaryotic translation initiation factor 3 subunit G & eTIF3g & 2.19 & n.s. \\
\hline P17092 & $30 S$ ribosomal protein S17 & S17 & 2.23 & n.s. \\
\hline NoDM61 & 30 S ribosomal protein S7 & S7 & n.s. & Suppressed \\
\hline A0A1S2Z5B3 & $50 S$ ribosomal protein $L 4$ & $\llcorner 4$ & n.s. & 0.46 \\
\hline A0A191UJA2 & $50 S$ ribosomal protein L14 & L14 & n.s. & Suppressed \\
\hline \multicolumn{5}{|c|}{ Protein processing and transporting } \\
\hline A0A1S2X9H9 & Heat shock $70 \mathrm{kDa}$ protein & HSP70 & 2.08 & n.s. \\
\hline G7IDZ4 & Heat shock protein $81-2$ & HSP81-2 & n.s. & 2.29 \\
\hline $11 \mathrm{~L} 314$ & Heat shock protein 90-1 & HSP90-1 & n.s. & Induced \\
\hline I1LD87 & Protein disulfide isomerase-like 7 & PDIL7 & Induced & n.s. \\
\hline A0A151T7Z7 & UDP-glucose:glycoprotein glucosyltransferase 1 & UGGT & 2.56 & n.s. \\
\hline
\end{tabular}


Table 2 Proteins and their fold changes in the leaves and roots of stylo under Mn toxicity (Continued)

\begin{tabular}{|c|c|c|c|c|}
\hline \multirow{2}{*}{$\begin{array}{l}\text { Accession } \\
\text { number }{ }^{\mathrm{a}} \text { ) }\end{array}$} & \multirow[t]{2}{*}{ Protein name $\left({ }^{b}\right)$} & \multirow{2}{*}{$\begin{array}{l}\text { Protein } \\
\text { abbreviation }\end{array}$} & \multicolumn{2}{|l|}{ Fold change } \\
\hline & & & Leaf (Mn/CK) & Root $(\mathrm{Mn} / \mathrm{CK})$ \\
\hline A0A1S2Z565 & $\begin{array}{l}\text { Dolichyl-diphosphooligosaccharide-protein } \\
\text { glycosyltransferase subunit STT3B }\end{array}$ & $\mathrm{STT} 3 \mathrm{~B}$ & Induced & n.s. \\
\hline \multicolumn{5}{|c|}{ Protein degradation } \\
\hline A0A072TU80 & Ubiquitin-conjugating enzyme & UBC & Induced & n.s. \\
\hline A0A151TZ12 & E3 ubiquitin-protein ligase UPL1 & UPL1 & Induced & n.s. \\
\hline A0A1S2Z415 & Leucine aminopeptidase 1-like & LAPL1 & Suppressed & n.s. \\
\hline \multicolumn{5}{|l|}{ Signaling } \\
\hline A0A1S3VLK4 & CBS domain-containing protein CBSX1 & CBSX1 & Induced & n.s. \\
\hline A0A072UP16 & Osmosensor histidine kinase & OHK & n.s. & Induced \\
\hline A0A151TSS1 & 14-3-3 like protein B & $14-3-3$ & 2.21 & n.s. \\
\hline A0A151SLL9 & Putative inactive receptor kinase & IRK & Induced & n.s. \\
\hline A0A0L9U108 & Serine/threonine-protein phosphatase & PP & Suppressed & n.s. \\
\hline A0A072UKS2 & PfkB family carbohydrate kinase & PfkB & Suppressed & n.s. \\
\hline G7JHIO & General regulatory factor 2 & GRF2 & Suppressed & n.s. \\
\hline I3S111 & RAB GTPase-like protein A1D & A1D & n.s. & Suppressed \\
\hline G7L1E7 & C2 calcium/lipid-binding and GRAM domain protein & CalBP & n.s. & Suppressed \\
\hline
\end{tabular}

Note: ${ }^{a}$ Database accession number from UniProt; ${ }^{\mathrm{b}}$ The name and functional categories of the proteins identified by LC-MS/MS. Stylo seedlings were grown under normal conditions for $30 \mathrm{~d}$ and then treated with $5(\mathrm{CK})$ or $400 \mu \mathrm{M}(\mathrm{Mn}) \mathrm{MnSO}_{4}$ for $10 \mathrm{~d}$. Differentially expressed proteins in the leaves and roots of RY5 regulated by $\mathrm{Mn}$ toxicity were identified using a label-free quantitative proteomics approach. n.s. represents no significant difference

hydroxymethyltransferase (SHMT) (Fig. 7 and Table 2). RCA and rbcL catalyze the most crucial step of carbon fixation within the photorespiration and Calvin cycle pathways. The reduction of photosynthesis in white birch (Betula platyphylla) under Mn toxicity has been attributed to the modification of rubisco and the inhibition of ribulose-1,5-bisphosphate regeneration through the Calvin cycle [40]. Furthermore, PGLP dephosphorylates the 2-phosphoglycolate produced by rubisco to generate glycolate, which can be further catalyzed by

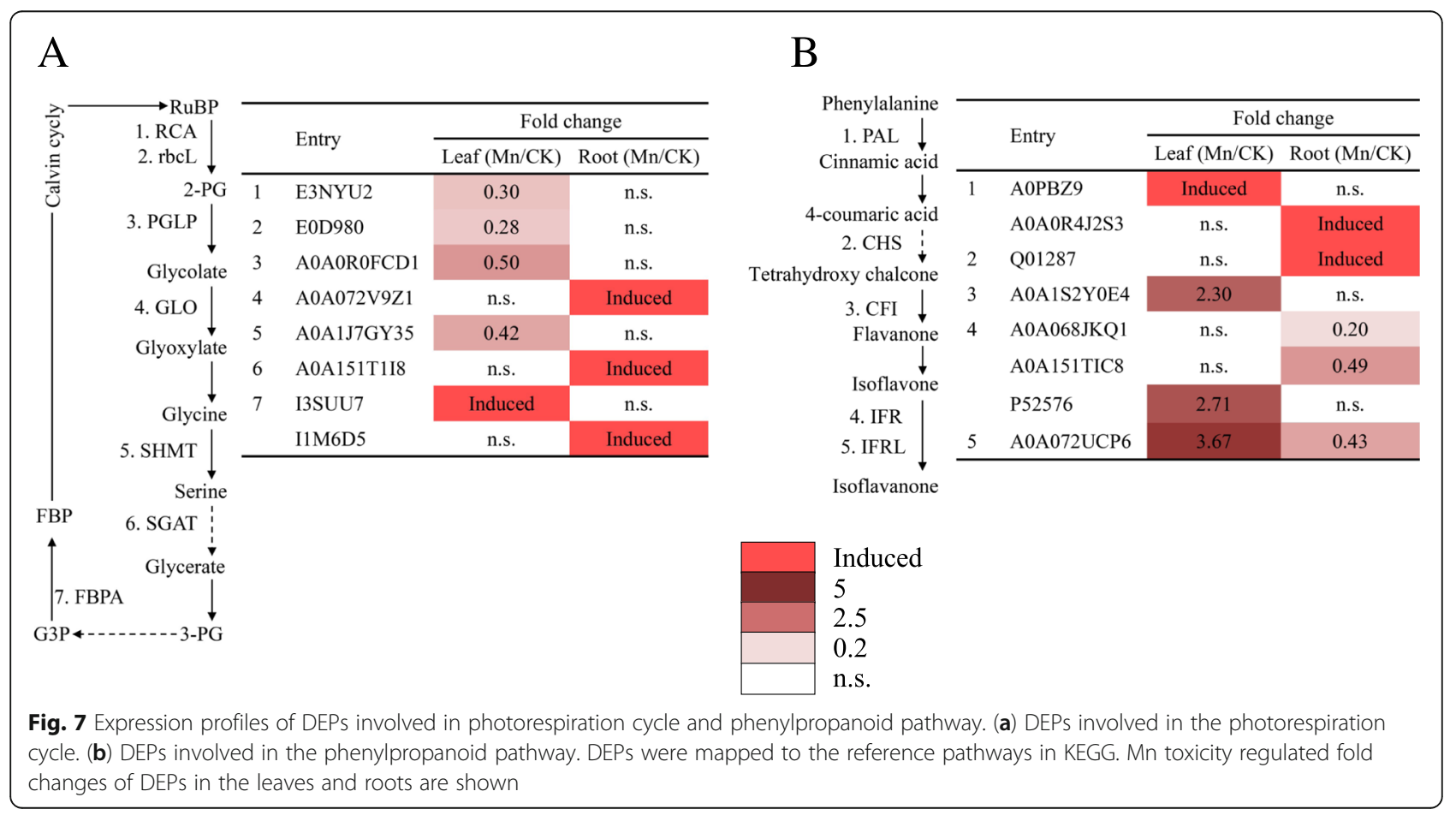




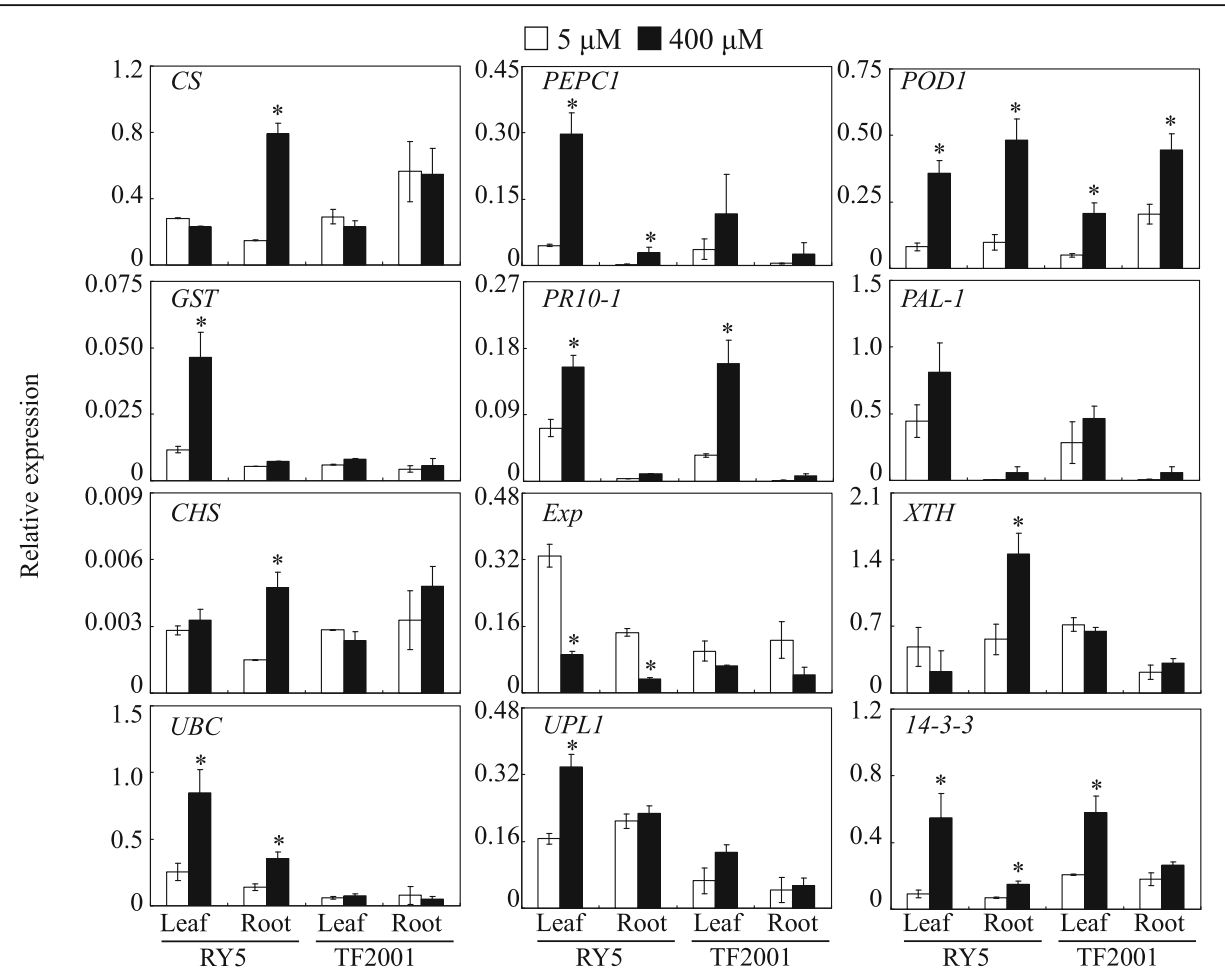

Fig. 8 Transcription levels of genes encoding excess Mn regulated proteins. qRT-PCR was performed to detect gene expression in stylo leaves and roots treated with 5 or $400 \mu \mathrm{M} \mathrm{MnSO}_{4}$. Each bar indicates the mean of three independent replicates with standard error. Asterisks indicate significant differences between $5 \mu \mathrm{M}$ and $400 \mu \mathrm{M} \mathrm{Mn}$ treatments at the $P=0.05$ level

peroxisomal (S)-2-hydroxy-acid oxidase (GLO) to produce glyoxylate, which facilitates glycine generation [41, 42]. SHMT catalyzes the interconversion of glycine and serine and is involved in controlling cell damage caused by salt and hypersensitive stress [43]. Interestingly, the abundance of fructose-bisphosphate aldolase (FBPA), which is involved in glycolysis and the Calvin cycle, was enhanced in leaves and roots of stylo under Mn toxicity (Fig. 7 and Table 2). The changes in abundance of the above proteins probably modulate the reduction of photosynthesis in the response of stylo to Mn toxicity.

\section{Defense response of RY5 to Mn toxicity}

In this study, accumulation of $\mathrm{H}_{2} \mathrm{O}_{2}$ and MDA was increased in the leaves and roots of stylo treated with excess Mn, especially in TF2001 (Fig. 2). Such accumulation may result in cellular damage through oxidative stress. The elimination of excess ROS stress via regulation of the antioxidant system is employed by plants to manage Mn toxicity $[11,17]$. Excess $M n$ increased the activities of SOD, POD and CAT (Fig. 3) and the concentrations of AsA and GSH in RY5 (Fig. 4), suggesting that antioxidant enzymes and the AsA-GSH cycle are most likely involved in ROS scavenging in stylo. Consistent with the increased POD activity under excess Mn, the abundances of seven PODs and POD1 gene transcripts were enhanced in stylo leaves under $\mathrm{Mn}$ toxicity, although other POD homologues exhibited different regulation in roots (Fig. 8 and Table 2). An increased accumulation of PODs has been found to modulate $\mathrm{Mn}$ oxidation and compartmentalization in cowpea [17].

Other defense response proteins, such as glutathione S-transferase (GST), pathogenesis-related proteins (PRs), chitinase (CHI) and polyphenol oxidase (PPO), were identified in this study (Table 2). Homologues of these proteins have been demonstrated to respond to abiotic stresses. For example, increased protein abundance of GST has been reported in roots of Arabidopsis under cadmium $(\mathrm{Cd})$ treatment [44]. Overexpression of GST in Arabidopsis decreases ROS accumulation under salinity, improving salt stress tolerance [45]. Furthermore, $\mathrm{CHI}$ acts as one of the second-line defense components involved in plant metal stress tolerance by affecting the metal binding and immobilization capability of the cell wall [46]. In addition, as a stress-related protein, PPO catalyzes the oxidation of polyphenols into quinones, and the expression of PPO is enhanced under $\mathrm{Cd}$ and mercury $(\mathrm{Hg})$ treatments [45]. Thus, enhancement of ROS scavenging and defense response may be important strategies for RY5 to counteract injuries arising from Mn-provoked oxidative damage. 


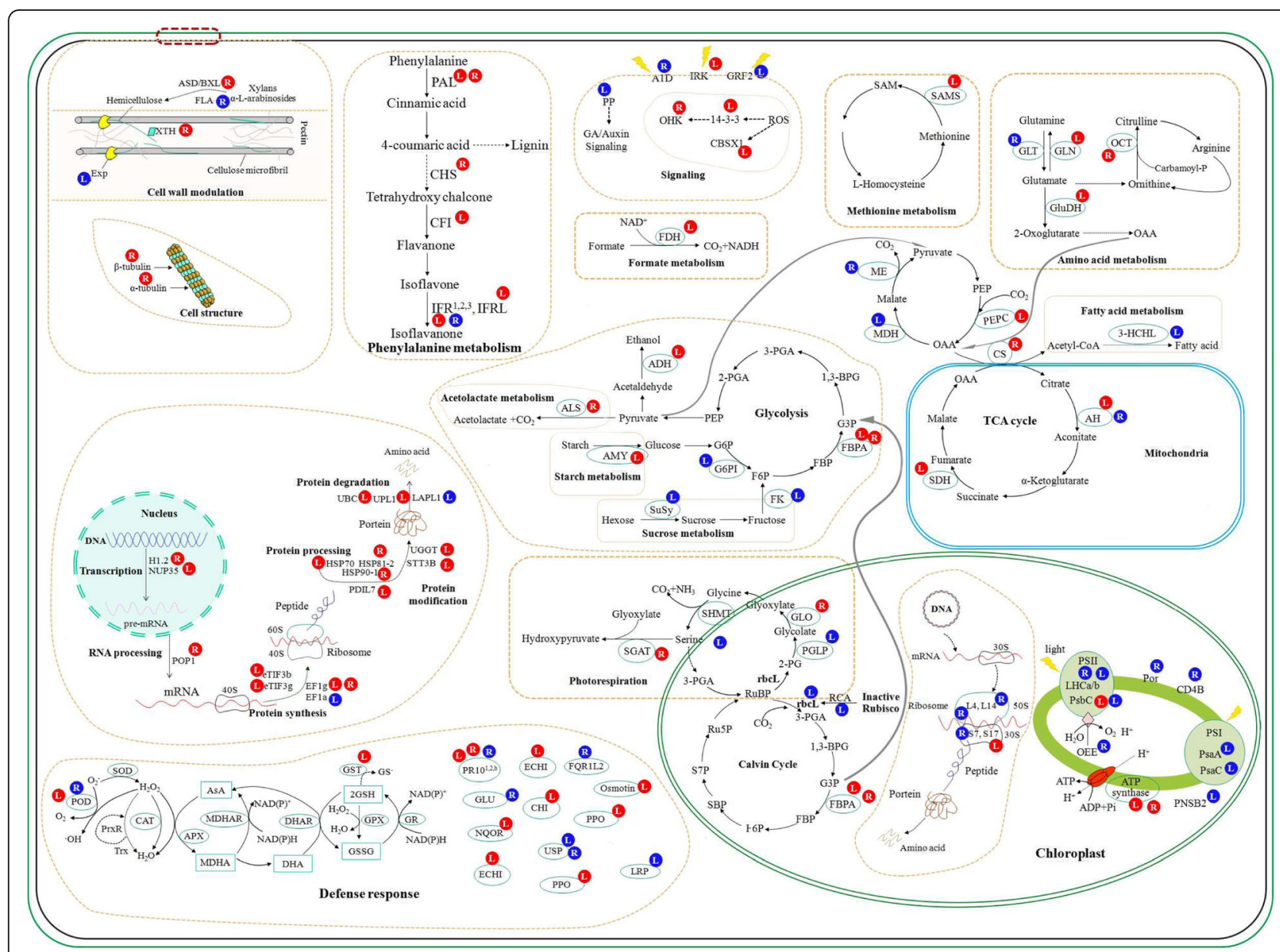

Fig. 9 Schematic presentation of molecular processes in the response of stylo to Mn toxicity. The identified proteins were integrated into specific pathways. Protein expression patterns in leaves $(L)$ and roots (R) are shown in red (increased) or blue (decreased), respectively

\section{Metabolism adjustment under Mn toxicity}

Metabolic processes have been found to respond to Mn toxicity in many plants [8]. In this study, a set of excess Mn-regulated DEPs were associated with specific pathways (Table 2), such as the TCA cycle, carbon fixation, amino acid and other metabolism, suggesting that complex changes arise in stylo during adaptation to $\mathrm{Mn}$ toxicity. Several proteins involved in the TCA cycle, including citrate synthase (CS), aconitate hydratase (AH) and succinate dehydrogenase (SDH), were differentially regulated by $\mathrm{Mn}$ toxicity in the leaves and roots of stylo (Fig. 9). CS catalyzes the combination of oxaloacetate (OAA) and acetyl CoA to produce citrate, which can isomerize into isocitrate via cis-aconitate catalyzed by $\mathrm{AH}$ [47]. Furthermore, several proteins involved in carbon fixation, including phosphoenolpyruvate carboxylase (PEPC), malate dehydrogenase (MDH) and malic enzyme (ME), were regulated by Mn toxicity in stylo leaves and roots in this study (Fig. 9). PEPC has been demonstrated to irreversibly catalyze the conversion of phosphoenolpyruvate (PEP) to OAA, which is catalyzed by
$\mathrm{MDH}$ to produce malate; malate is then catalyzed by ME to generate pyruvate [48]. Although important roles of organic acids (e.g., citrate and malate) in Mn detoxification are suggested in some plants, including cowpea, ryegrass, white clover and Phytolacca americana [23, 49, 50], only one $\mathrm{MDH}$ has been found to regulate malate synthesis and exudation, conferring high $\mathrm{Mn}$ tolerance in stylo [25]. Thus, the potential roles of the candidate DEPs described above in the management of Mn toxicity in stylo through the regulation of organic acid metabolism warrant further study.

Additionally, amino acid metabolism-related proteins, such as glutamine synthetase (GLN) and glutamate synthase (GLT) and glutamate dehydrogenase (GluDH), were identified in this study (Table 2). Furthermore, $\mathrm{S}$-adenosylmethionine synthetase (SAMS), which catalyzes the formation of SAM, a compound involved in the biosynthesis of sulfur amino acids, polyamines and ethylene [51], was found to be upregulated by Mn toxicity in the leaves of stylo (Fig. 9). The expression of SAMS has also been found to be modulated by arsenic 
treatments [52]. Therefore, our results suggest that adjustment of amino acid metabolism might be important in the response of stylo to Mn toxicity.

\section{DEPs involved in the phenylpropanoid pathway}

Although several secondary metabolites have been reported to be regulated by excess $\mathrm{Mn}$ in plants, such as phenolics and callose in cowpea [17], lignin and flavonoids in rice [35] and phenylalanin in Populus cathayana [53], no phenylpropanoid pathway-related proteins have previously been identified using proteomic techniques. In the present study, key proteins involved in the phenylpropanoid pathway, including phenylalanine ammonia-lyase (PAL), chalcone synthase (CHS), chalcone-flavonone isomerase family protein (CFI), and isoflavone reductase (IFR), were found to be upregulated in the leaves or roots of stylo under Mn toxicity, whereas the other homologues of IFR were downregulated in the roots (Fig. 7 and Table 2). PAL is the primary enzyme in the phenylpropanoid pathway, of which the products, such as flavonoids and lignins, are key compounds in abiotic stress tolerance [54]. CHS is involved in the synthesis of tetrahydroxy chalcone, whereas CFI catalyzes the intramolecular cyclization of bicyclic chalcones into tricyclic (S)-flavanones, and IFRs then catalyze the reduction from achiral isoflavones to chiral isoflavanones $[55,56]$. The expression levels of PAL, CHS, and IFR are enhanced by $\mathrm{Cd}$ and lead treatment as well as by salinity stress [57-59]. Similarly, in this study, the CHS transcript was also increased by excess Mn in RY5 roots (Fig. 8). The results of the present study suggest that the phenylpropanoid pathway is enhanced in stylo adaptation to excess $\mathrm{Mn}$ toxicity. This novel hypothesis merits further study.

\section{DEPs involved in cytoskeleton and cell wall modulation}

In this study, cytoskeleton-related proteins, such as tubulin alpha chain ( $\alpha$-tubulin) and tubulin beta-1 chain ( $\beta$-tubulin), and cell-wall-associated proteins, such as expansin (Exp), were regulated by Mn toxicity in stylo (Table 2). Tubulin is the major constituent of microtubules, which are the basic components of the cytoskeleton and participate in cell division and elongation. Suppression of $\alpha$-tubulin results in decreased panicle elongation during drought stress in rice [60]. Expansin plays important roles in the regulation of cell wall extension and expansion [61]. Inhibition of plant growth is observed in tobacco overexpressing TaEXPB23 from wheat and in tomato overexpressing CsExp1 from Cucumis sativus [61, 62]. Interestingly, another cell-wall-associated protein, xyloglucan endotransglucosylase/hydrolase (XTH), was found, for the first time, to be upregulated by $\mathrm{Mn}$ toxicity in stylo roots (Table 2). Furthermore, $X T H$ expression level was increased by $\mathrm{Mn}$ toxicity in RY5 roots (Fig. 8). XTH catalyzes xyloglucan endohydrolysis (XEH) and/or endotransglycosylation (XET), thereby controlling cell wall extension and hemicellulose accumulation [63]. It has been reported that disruption of XTH31 in Arabidopsis results in higher $\mathrm{Al}$ resistance than in wild type, as reflected by reduced inhibition of root growth under Al toxicity [64]. Therefore, the regulation of proteins associated with the cytoskeleton and cell wall structure may be important for root growth in stylo exposed to Mn toxicity.

\section{Transcriptional regulation and protein turnover in stylo}

In this study, two transcription-related proteins, one nuclear pore complex protein NUP35 (NUP35) in leaves and one histone H1.2 (H1.2) in roots, were upregulated in stylo under Mn toxicity (Fig. 9 and Table 2). The nuclear pore complex facilitates the exchange of macromolecules between the cytoplasm and nucleoplasm [65]. Histones play a central role in transcriptional regulation, DNA repair and chromosomal stability and are involved in stress tolerance in plants [66]. In addition, the abundance of one RNA processing-related protein, ribonuclease $\mathrm{P} / \mathrm{MRP}$ protein subunit POP1 (POP1), which is involved in the generation of mature tRNA molecules by cleaving their 5' ends [67], was increased in the roots of stylo under Mn toxicity (Fig. 9 and Table 2). The transcriptional regulation and RNA processing might be activated in the leaves and roots of stylo under $\mathrm{Mn}$ toxicity.

Several proteins involved in protein synthesis were identified in the leaves or roots of stylo (Fig. 9 and Table 2). For example, two elongation factors (e.g., EF1a and EF1g) involved in the promotion of GTP-dependent binding of aminoacyl-tRNA to ribosomes [68], and two eukaryotic translation initiation factors (e.g., eTIF3b and eTIF3g) that stimulate the binding of mRNA and methionyl-tRNAi to the $40 \mathrm{~S}$ ribosome [69] were regulated by $\mathrm{Mn}$ toxicity in stylo leaves and roots (Fig. 9 and Table 2). Furthermore, the accumulation of two proteins involved in protein degradation, ubiquitin-conjugating enzyme (UBC) and E3 ubiquitin-protein ligase (UPL1), was induced in stylo leaves by $\mathrm{Mn}$ toxicity (Table 2). Interestingly, the expression levels of $U B C$ and UPL1 were also found to be increased under excess $\mathrm{Mn}$ conditions in RY5 leaves (Fig. 8), suggesting that ubiquitindependent protein degradation is activated in the RY5 response to $\mathrm{Mn}$ toxicity. Although the exact functions and mechanisms of these DEPs involved in protein synthesis and degradation remain largely unknown, our results suggest that the regulation of protein turnover might be an important process in the response of stylo to Mn toxicity. Future investigation of 
the functions of these proteins will help reveal the mechanisms of high Mn tolerance in stylo.

\section{DEPs involved in signal sensing and transduction}

In this study, several proteins associated with specific signaling pathways, including CBS domain-containing protein CBSX1 (CBSX1), osmosensor histidine kinase $(\mathrm{OHK})$, serine/threonine protein phosphatase (PP), and 14-3-3 like protein (14-3-3), were found to be regulated by $\mathrm{Mn}$ toxicity in stylo (Fig. 9 and Table 2). For example, 14-3-3 proteins are involved in various metabolic processes and signaling pathways through interactions with numerous proteins in plant cells [70]. The OHK protein functions as an osmosensor and transmits stress signals to a downstream mitogen-activated protein kinase (MAPK) cascade [71]. Overexpression of ATHK1, a histidine kinase, results in increased water stress tolerance in Arabidopsis by regulating ABA signaling [72]. In addition, serine/threonine PP possesses phosphatase activity toward para-nitrophenyl phosphate (pNPP) in vitro and acts as a positive regulator in the gibberellin (GA) and auxin signaling pathways, which regulate plant growth and development [73]. Therefore, a sophisticated signaling network may be involved in the response of stylo to Mn toxicity, and further investigation of these proteins is required.

\section{Conclusion}

In conclusion, the present study demonstrated that the stylo genotype RY5 had Mn tolerance superior to that of TF2001. The capability of RY5 to tolerate Mn toxicity was related to its reduced $\mathrm{Mn}$ absorption and stimulation of antioxidant protection, which in turn alleviated oxidative stress. The physiological and proteomic results suggest that a coordinately regulated accumulation of proteins associated with ROS scavenging, defense response, the phenylpropanoid pathway and protein metabolism helps stylo tolerate Mn toxicity. This study not only lays a foundation for further study of Mn tolerance mechanisms in tropical legumes but also provides candidate gene resources for breeding crop varieties tolerant to $\mathrm{Mn}$ toxicity through genetic improvement approaches.

\section{Methods}

\section{Plant growth and treatments}

In this study, nine stylo (Stylosanthes guianensis) genotypes, selected from the colony of its parent 'CIAT184' [74], were used to analyse their variability of $\mathrm{Mn}$ tolerance. The stylo seeds were provided by the Tropical Pasture Research Center, Institute of Tropical Crop Genetic Resources, Chinese Academy of Tropical Agricultural Sciences, Hainan Province, China. After seed germination for $3 \mathrm{~d}$, stylo seedlings were transferred to a hydroponic box with $12 \mathrm{~L}$ of Hoagland's nutrient solution [25]. The nutrient solution $\mathrm{pH}$ was adjusted to 5.8 using $\mathrm{H}_{2} \mathrm{SO}_{4}$ or $\mathrm{KOH}$. Experiments were conducted in a greenhouse at the Institute of Tropical Crop Genetic Resources, Chinese Academy of Tropical Agricultural Sciences, Hainan Province, China (19 $30^{\prime} \mathrm{N}$, $\left.109^{\circ} 30^{\prime} \mathrm{E}\right)$. After $30 \mathrm{~d}$ of growth, the uniform seedlings were transferred to fresh Hoagland's nutrient solution supplied with 5 or $400 \mu \mathrm{M} \mathrm{MnSO}_{4}$ (pH 5.0) as previously described [25]. Stylo plants treated with $5 \mu \mathrm{M} \mathrm{MnSO}$ were used as the control. After $10 \mathrm{~d}$ of Mn treatments, both the shoots and roots were separately measured.

Two stylo genotypes contrasting in Mn tolerance, 'RY5' and 'TF2001', were selected for further analysis. After $30 \mathrm{~d}$ of growth, the uniform seedlings were subjected to 5 or $400 \mu \mathrm{M} \mathrm{MnSO}{ }_{4}$ (pH 5.0) treatments. After $10 \mathrm{~d}$ of Mn treatments, both the shoots and roots were separately harvested for further analysis. Each treatment included four biological replicates. An individual hydroponic box containing three seedlings of each stylo genotype was considered one biological replicate.

\section{Determination of chlorophyll concentration and chlorophyll fluorescence parameters}

Chlorophyll concentration in the leaves of stylo was determined according to the SPAD value measured by SPAD502 (Top Instruments Inc., China). Four chlorophyll fluorescence parameters, including $F \mathrm{v} / F \mathrm{~m}$, ФPSII, 1-qL and ETR, were measured by a pulse-modulated fluorometer Model FMS-2 (Hansatech Instruments Ltd., UK) according to the manufacturer's instructions. The leaves were dark-adapted for $20 \mathrm{~min}$ before $F \mathrm{v} / F \mathrm{~m}$ analysis. $F \mathrm{v} / F \mathrm{~m}$ was calculated as $F \mathrm{v} / F \mathrm{~m}=\left(F \mathrm{~m}-F_{\mathrm{o}}\right) / F \mathrm{~m}$, where $F_{\mathrm{o}}$ and $F \mathrm{~m}$ are the initial fluorescence yield and the maximum fluorescence yield, respectively. The leaves were then illuminated with actinic light. ФPSII was calculated as $\Phi$ PSII $=\left(F \mathrm{~m}^{\prime}-F \mathrm{~s}\right) / F \mathrm{~m}^{\prime}$, where $F \mathrm{~m}^{\prime}$ and $F \mathrm{~s}$ are the maximal and steady-state fluorescence yields in a light-adapted state, respectively. 1-qL was calculated as $1-\mathrm{qL}=1-\left(F \mathrm{~m}^{\prime}-F \mathrm{~s}\right) /\left(F \mathrm{~m}^{\prime}-F \mathrm{o}^{\prime}\right) \cdot F \mathrm{o}^{\prime} / F \mathrm{~s}$, where $F \mathrm{o}^{\prime}$ is the minimal fluorescence yields in a light-adapted state [75]. ETR was calculated as ETR = ФPSII.PPFD $\cdot 0.84 \cdot 0.5$, where PPFD is an incident photosynthetic photon flux density.

\section{Determination of photosynthetic indexes}

The $\mathrm{Pn}, \mathrm{Ci}$ and $\mathrm{Gs}$ values were measured at 9:00 a.m. using a portable photosynthesis system LI-6400XT (LI-COR, USA) according to the manufacturer's instructions. All the measurements were conducted at a constant flow rate of $400 \mu \mathrm{mol} \mathrm{s}^{-1}$ and at saturation irradiance with PPFD of $1000 \mu \mathrm{mol} \mathrm{m}^{-2} \mathrm{~s}^{-1}$. Leaf temperature was controlled at $30^{\circ} \mathrm{C}$, and the $\mathrm{CO}_{2}$ concentration was set at $385 \mu \mathrm{mol} \mathrm{CO} \mathrm{mol}^{-1}$. 


\section{Determination of $\mathrm{Mn}$ concentrations}

Shoot and root samples were oven dried at $105^{\circ} \mathrm{C}$ for $30 \mathrm{~min}$ and further dried at $75^{\circ} \mathrm{C}$. After determination of the shoot and root dry weight, the samples were ground into powder. Then, approximately $0.07 \mathrm{~g}$ samples were burned to ash in a muffle furnace at $600{ }^{\circ} \mathrm{C}$ for $10 \mathrm{~h}$. After that, the sample ash was thoroughly dissolved in 7 $\mathrm{mL}$ of $100 \mathrm{mM} \mathrm{HCl}$. Mn concentrations were determined using atomic absorption spectroscopy. A standard curve was used to quantify the Mn concentration in each sample as previously described [25].

\section{Analysis of $\mathrm{H}_{2} \mathrm{O}_{2}$ and MDA}

$\mathrm{H}_{2} \mathrm{O}_{2}$ and MDA were measured using commercial chemical assay kits (Comin Ltd., China) as previously described [76]. Leaf and root samples were ground into powder in liquid nitrogen. $\mathrm{H}_{2} \mathrm{O}_{2}$ determination was carried out according to the assay kit, which was based on the titanium sulfate reaction. Briefly, approximately $0.1 \mathrm{~g}$ samples were extracted in $1 \mathrm{~mL}$ of acetone at $4{ }^{\circ} \mathrm{C}$. The homogenates were centrifuged at $12,000 \times g$ for $10 \mathrm{~min}$ at $4{ }^{\circ} \mathrm{C}$, and the supernatants were then collected. Subsequently, $250 \mu \mathrm{L}$ supernatant was mixed with $25 \mu \mathrm{L}$ buffer II and $50 \mu \mathrm{L}$ buffer III from the assay kit. The mixture was centrifuged at $4000 \times g$ for $10 \mathrm{~min}$ at $25^{\circ} \mathrm{C}$, and the resulting pellets were then collected and dissolved in buffer IV from the assay kit. The $\mathrm{H}_{2} \mathrm{O}_{2}$ concentration was spectrophotometrically detected at $415 \mathrm{~nm}$ with a spectrophotometer (UV-2010, Hitachi, Japan), and calculated by comparison with a standard curve.

For MDA determination, approximately $0.1 \mathrm{~g}$ samples were ground in $1 \mathrm{~mL}$ of extraction buffer I from the assay kit at $4{ }^{\circ} \mathrm{C}$, which was based on the thiobarbituric acid (TBA) reaction. The homogenates were centrifuged at $12,000 \times g$ for $10 \mathrm{~min}$ at $4{ }^{\circ} \mathrm{C}$, and the supernatants were then collected. $0.1 \mathrm{~mL}$ supernatant was homogenized into $0.3 \mathrm{~mL}$ of a reaction buffer II from the assay kit. The mixture was heated at $95^{\circ} \mathrm{C}$ for $30 \mathrm{~min}$, immediately cooled in an ice bath, and centrifuged at $12,000 \times g$ for $10 \mathrm{~min}$ at $25^{\circ} \mathrm{C}$. The MDA concentration was determined at $532 \mathrm{~nm}$ and $600 \mathrm{~nm}$, and calculated according to the instructions of manufacturers in the assay kit.

\section{Determination of enzyme activities and AsA and GSH concentrations}

The activities of SOD, POD and CAT were measured using commercial chemical assay kits (Comin Ltd., China). Approximately $0.1 \mathrm{~g}$ of leaf and root samples were ground in $1 \mathrm{~mL}$ of extraction buffer from their respective assay kits at $4{ }^{\circ} \mathrm{C}$. After centrifugation at $12,000 \times g$ for $10 \mathrm{~min}$ at $4{ }^{\circ} \mathrm{C}$, the supernatants were collected and used for determination of the enzyme activities [76]. Briefly, SOD activity was detected based on the nitroblue tetrazolium chloride (NBT) reaction. $36 \mu \mathrm{L}$ supernatant was mixed with $90 \mu \mathrm{L}$ buffer I, $200 \mu \mathrm{L}$ buffer II, $4 \mu \mathrm{L}$ buffer III and $70 \mu \mathrm{L}$ buffer IV from the assay kit. The reaction mixture was exposed to light for $30 \mathrm{~min}$, and then the absorbance was measured at $560 \mathrm{~nm}$ with a spectrophotometer (UV-2010, Hitachi, Japan). The SOD activity was determined according to the instructions of manufacturers. POD activity was determined based on the guaiacol method. The reaction buffer contained $20 \mu \mathrm{L}$ supernatant, $240 \mu \mathrm{L}$ buffer I, $60 \mu \mathrm{L}$ buffer II, $60 \mu \mathrm{L}$ buffer III and $120 \mu \mathrm{L} \mathrm{dH}_{2} \mathrm{O}$ from the assay kit. POD activity was determined at $470 \mathrm{~nm}$ within $1 \mathrm{~min}$, and defined as an absorbance change of 0.01 units per min. For CAT activity determination, the reaction buffer contained $20 \mu \mathrm{L}$ supernatant and $380 \mu \mathrm{L}$ buffer I from the assay kit. The CAT activity was determined at $240 \mathrm{~nm}$ within $1 \mathrm{~min}$, and defined as the amount of protein required to oxidize $1 \mathrm{nmol} \mathrm{H}_{2} \mathrm{O}_{2}$ per min. The protein content in each sample was measured according to Bradford [77]. The specific enzyme activities were expressed as $\mathrm{U} \mathrm{mg}^{-1}$ protein.

For AsA and GSH determination, approximately 0.1 $\mathrm{g}$ of leaf and root samples were ground in $1 \mathrm{~mL}$ of extraction buffer from their respective assay kits (Comin Ltd., China) at $4{ }^{\circ} \mathrm{C}$. The homogenates were centrifuged at $12,000 \times g$ for $15 \mathrm{~min}$ at $4{ }^{\circ} \mathrm{C}$, and the supernatants were then collected for AsA and GSH analysis [76]. For AsA determination, the reaction buffer contained $40 \mu \mathrm{L}$ supernatant, $320 \mu \mathrm{L}$ buffer I and $40 \mu \mathrm{L}$ buffer II from the assay kit. The AsA concentration was determined at $265 \mathrm{~nm}$ within $1 \mathrm{~min}$, and calculated by comparison with a standard curve. For GSH analysis, the reaction buffer contained $40 \mu \mathrm{L}$ supernatant, $280 \mu \mathrm{L}$ buffer I and $80 \mu \mathrm{L}$ buffer II from the assay kit. After incubation at $30^{\circ} \mathrm{C}$ for $5 \mathrm{~min}$, the GSH concentration was determined at $412 \mathrm{~nm}$. A standard curve was used to quantify the GSH concentration in each sample. For blank controls, $\mathrm{dH}_{2} \mathrm{O}$ was used instead of supernatant in the reaction buffer. All of the experiments included three biological replicates.

\section{Label-free quantitative proteomics}

The label-free proteomic approach was conducted at Shanghai Applied Protein Technology Company (APT Ltd., China). For protein extraction, leaf and root proteins were extracted using a previously described method [25]. Briefly, approximately $3 \mathrm{~g}$ samples were homogenized in modified Tris- $\mathrm{HCl}$ ( $\mathrm{pH} 8.8$ ) extraction buffer. After the homogenates were centrifuged, the supernatants were incubated with methanol at $-20^{\circ} \mathrm{C}$. After centrifugation, the resulting pellets were washed with acetone and ethanol. Finally, the resulting proteins were dissolved in SDT buffer (4\% SDS, $100 \mathrm{mM} \mathrm{DTT}$, $150 \mathrm{mM}$ Tris- $\mathrm{HCl}, \mathrm{pH} 8.0)$. The protein content of each 
sample was determined using the BCA Protein Assay Kit (Bio-Rad, USA).

For filter-aided sample preparation, $200 \mu \mathrm{g}$ of protein extract for each sample was mixed with UA buffer ( $8 \mathrm{M}$ urea, $150 \mathrm{mM}$ Tris- $\mathrm{HCl}, \mathrm{pH} 8.0)$. The detergent, DTT and other components in the mixture were removed by repeated ultrafiltration (Microcon units, $10 \mathrm{kD}$ ). Then, the proteins were alkylated with $100 \mu \mathrm{L}$ of $100 \mathrm{mM}$ iodoacetamide in UA buffer at room temperature for 30 min in the dark. The filters were washed three times with $100 \mu \mathrm{L}$ of UA buffer and then twice with $100 \mu \mathrm{L}$ of $25 \mathrm{mM} \mathrm{NH}_{4} \mathrm{HCO}_{3}$ buffer. The proteins were then digested with $4 \mu \mathrm{g}$ trypsin (Promega, WI) in $40 \mu \mathrm{L}$ of 25 $\mathrm{mM} \mathrm{NH} \mathrm{HCO}_{3}$ buffer overnight at $37^{\circ} \mathrm{C}$, and the resulting peptides were recovered by centrifugation. The peptides of each sample were desalted on C18 Empore ${ }^{\mathrm{Tw}}$ SPE Cartridges (Sigma, Germany) and concentrated by vacuum centrifugation, which was followed by reconstitution in $40 \mu \mathrm{L}$ of $0.1 \%(\mathrm{v} / \mathrm{v})$ formic acid.

For mass spectrometry, the peptide mixture was loaded onto a $2 \mathrm{~cm} \times 100 \mu \mathrm{m}$ reversed-phase C18 trap column (Thermo Fisher Scientific, Schwerte, Germany) and separated on a $10 \mathrm{~cm} \times 75 \mu \mathrm{m} \mathrm{C18}$ analytical column (Thermo Fisher Scientific) in mobile phases A (0.1\% formic acid) and B ( $84 \%$ acetonitrile and $0.1 \%$ formic acid) at a flow rate of $300 \mathrm{~nL} / \mathrm{min}$. The gradient was increased to $55 \%$ of buffer B in 110 min and to $100 \%$ of buffer B in $5 \mathrm{~min}$, with a hold at $100 \%$ of buffer B for $5 \mathrm{~min}$. LC-MS/MS analysis was performed on a $\mathrm{Q}$ Exactive mass spectrometer (Thermo Fisher Scientific, Schwerte, Germany) coupled to an Easy nLC system (Thermo Fisher Scientific) for $120 \mathrm{~min}$. MS data were acquired using a data-dependent top 10 method, dynamically choosing the most abundant precursor ions from the survey scan $(300-1800 \mathrm{~m} / \mathrm{z})$. The resolution was set to 70,000 for the MS scans and 17,500 for the data-dependent MS/MS scans. The raw data have been deposited to the ProteomeXchange Consortium (http:// proteomecentral.proteomexchange.org) via the PRIDE [78] partner repository with the dataset identifier PXD012379.

For protein identification and quantification, the MS data were analyzed using MaxQuant software version 1.5.3.17 (Max Planck Institute of Biochemistry in Martinsried, Germany). Database searches were conducted against Papilionoideae in UniProt (http://www.uniprot. org/), which contained 490,695 sequences when updated on July 6,2017 . The mass tolerance was set to $20 \mathrm{ppm}$, and the main search tolerance was $6 \mathrm{ppm}$, allowing for two missed trypsin cleavages. Cysteine carbamidomethylation was set as a fixed modification. Methionine oxidation and $\mathrm{N}$-acetylation protein were set as variable modifications. The false discovery rate (FDR) was set to 0.01 for peptide and protein identification (Additional files 3 and 4). MaxQuant also added a list of common contaminants to the database to avoid false discoveries from contaminant proteins. The experiments contained three biological replicates. Proteins identified at least twice in the three biological replicates were considered quantifiable proteins. Proteins with abundance changes of more than 2-fold and cutoff values of $P<0.05$ were defined as differentially expressed between the groups (Additional file 5). The Blast2GO (version 3.3.5) program was used for protein mapping and functional annotation against the GO database. The online Kyoto Encyclopedia of Genes and Genomes (KEGG) database (http://www.genome.jp/kegg/) was used to classify and group the identified proteins.

\section{Quantitative real-time PCR (qRT-PCR) analysis}

Total RNA from stylo leaves and roots were extracted using the Trizol reagent (Invitrogen, USA) according to the manual. M-MLV reverse transcriptase (Promega, USA) was used for first strand cDNA synthesis. qRT-PCR analysis was performed using SYBR Premix Ex Taq II (Takara, China), and the reaction was monitored by a Rotor-Gene Q system (Qiagen, Germany). qRT-PCR reaction were set as follows: $95^{\circ} \mathrm{C}$ for $1 \mathrm{~min}$, 40 cycles of $95^{\circ} \mathrm{C}$ for $15 \mathrm{~s}, 60^{\circ} \mathrm{C}$ for $15 \mathrm{~s}$ and $72^{\circ} \mathrm{C}$ for $30 \mathrm{~s}$. Fluorescence data were collected at $72^{\circ} \mathrm{C}$. The qRT-PCR primers for the corresponding genes encoding the identified proteins are shown in Additional file 6 . Relative gene expression levels were calculated relative to the expression levels of the housekeeping gene $S g E F-1 a$ [25]. Gene expression analysis contained three biological replicates.

\section{Statistical analysis}

Microsoft Excel 2003 (Microsoft Company, USA) was used to calculate means and standard errors. Data analysis was performed by one-way ANOVA and the Student's $t$ test using the SPSS program (SPSS Institute, USA, version 13.0).

\section{Additional files}

Additional file 1: Figure S1. Effects of Mn treatments on the growth of different stylo genotypes. (a) SPAD. (b) Plant dry weight. After $30 \mathrm{~d}$ of normal growth, stylo seedlings were treated with 5 or $400 \mu \mathrm{M} \mathrm{MnSO}_{4}$ for $10 \mathrm{~d}$. Each bar indicates the mean of four biological replicates with standard error. The same letter represents no significant difference at the $P=0.05$ level. (PDF $167 \mathrm{~kb}$ )

Additional file 2: Table S1. Number of peptides, proteins and DEPS identified from the samples. (XLSX $9 \mathrm{~kb}$ )

Additional file 3: Table S2. Information of peptides identified from the leaves and roots of stylo. (XLSX $1836 \mathrm{~kb}$ )

Additional file 4: Table S3. Information of proteins identified from the leaves and roots of stylo. (XLSX $789 \mathrm{~kb})$ 
Additional file 5: Table S4. Differentially expressed proteins identified from the leaves and roots of stylo. (XLSX $1133 \mathrm{~kb}$ )

Additional file 6: Table S5. List of primers used in the study for gene expression analysis. (XLSX $9 \mathrm{~kb}$ )

\section{Abbreviations}

14-3-3: 14-3-3 like protein B; A1D: RAB GTPase-like protein A1D; ADH: Alcohol dehydrogenase; AH: Aconitate hydratase; ALS: Acetolactate synthase; AMY: Alpha-amylase; ASD/BXL: Alpha-L-arabinofuranosidase/betaD-xylosidase; CBSX1: CBS domain-containing protein CBSX1; CD4B: ATPdependent Clp protease ATP-binding subunit clpA like CD4B; CFI: Chalconeflavonone isomerase family protein; CHI: Chitinase class Ib; CHS: Chalcone synthase 2; CS: Citrate synthase; ECHI: Endochitinase; EF1a: Elongation factor 1-alpha; EF1g: Elongation factor 1-gamma; eTIF3b: Eukaryotic translation initiation factor 3 subunit B; eTIF3g: Eukaryotic translation initiation factor 3 subunit G; Exp: expansin; FBPA: Fructose-bisphosphate aldolase; FDH: Formate dehydrogenase; FLA: Fasciclin-like arabinogalactan protein 12; FQR1L2: Probable NAD(P)H dehydrogenase (Quinone) FQR1-like 2; G6PI: Glucose-6-phosphate isomerase; GLN: Glutamine synthetase; GLO: Peroxisomal (S)-2-hydroxy-acid oxidase GLO1; GLT: Glutamate synthase; GLU: beta-1,3-glucanase; GluDH: Glutamate dehydrogenase; GRF2: General regulatory factor 2; GST: Probable glutathione S-transferase; H1.2: Histone H1.2; HSP70: Heat shock 70 kDa protein; HSP81-2: Heat shock protein 81-2; HSP90-1: Heat shock protein 90-1; IFR: Isoflavone reductase; IFRL: Isoflavone reductase-like protein; IRK: Putative inactive receptor kinase; L14: 50 S ribosomal protein L14; L4: 50 S ribosomal protein L4; LAPL1: leucine aminopeptidase 1-like; LHCa/b: Chlorophyll a-b binding protein; LRP: Lightregulated protein; $\mathrm{MDH}$ : Cytosolic malate dehydrogenase; ME: Malic enzyme: NQOR: NAD(P)H:quinone oxidoreductase; NUP35: Nuclear pore complex protein NUP35; OCT: Ornithine carbamoyltransferase; OEE: Photosystem II oxygen-evolving enhancer protein; OHK: Osmosensor histidine kinase; Osmotin: Osmotin-like protein; PAL: Phenylalanine ammonia-lyase; PDIL7: Protein disulfide isomerase-like 7; PEPC: Phosphoenolpyruvate carboxylase; PGLP: Phosphoglycolate phosphatase; PNSB2: Photosynthetic NDH subunit of subcomplex B 2; POD: Peroxidase; POP1: Ribonucleases P/ MRP protein subunit POP1; Por: NADPH-protochlorophyllide oxidoreductase; PP: Serine/threonine-protein phosphatase; PPO: Polyphenol oxidase; PR10: Pathogenesis-related protein 10; PsaA: Photosystem I P700 chlorophyll a apoprotein A1: PsaC: Photosystem I iron-sulfur center; PsbC: Photosystem II CP43 reaction center protein; QOR: Quinone oxidoreductase-like protein 2 homolog; rbcL: Ribulose bisphosphate carboxylase large chain; RCA: Rubisco activase 2; S17: 30 S ribosomal protein S17; S7: 30 S ribosomal protein S7; SAMS: S-adenosylmethionine synthase; SDH: Succinate dehydrogenase; SGAT: Serine-glyoxylate aminotransferase; SHMT: Serine hydroxymethyltransferase; STT3B: Dolichyl-diphosphooligosaccharide---protein glycosyltransferase subunit STT3B; SuSy: Sucrose synthase 2; UBC: Ubiquitinconjugating enzyme; UGGT: UDP-glucose:glycoprotein glucosyltransferase 1; UPL1: E3 ubiquitin-protein ligase UPL1; USP: Universal stress protein; XTH: Xyloglucan endotransglucosylase/hydrolase; a-tubulin: Tubulin alpha chain; $\beta$-tubulin: Tubulin beta-1 chain

\section{Acknowledgments}

We sincerely thank American Journal Experts (https://www.aje.com/) for their help with English language editing.

\section{Funding}

The research was financially supported by the National Natural Science Foundation of China (31801951, 31672483, 31861143013), the Young Talents Academic Innovation Project of Hainan Association for Science and Technology (QCXM201715), the Key Research and Development Program of Hainan (ZDYF2018048), the Central Public-interest Scientific Institution Basal Research Fund for CATAS (1630032018004), and the Modern Agro-industry Technology Research System (CARS-34). The authors declare that none of the funding bodies have any role in the design of the study or collection, analysis, and interpretation of data as well as in writing the manuscript.

\section{Availability of data and materials}

The datasets are included in this article and its Additional files are available from the corresponding author on reasonable request. The mass spectrometry data have been deposited to the ProteomeXchange
Consortium via the PRIDE partner repository with the dataset identifier PXD012379.

\section{Authors' contributions}

Z.C. conceived and designed the research. P.L., R.H., X.H., Y.J. and J.F.L. performed the physiological experiments. P.L. and R.H. carried out the proteomic and qRT-PCR analysis. P.L., R.H., J.J.L. and Q.L. analyzed the data. L.L. and G.L. provided many critical suggestions for this work. Z.C. wrote the article. All authors read and approved the final manuscript.

\section{Ethics approval and consent to participate}

Not applicable.

\section{Consent for publication}

Not applicable.

\section{Competing interests}

The authors declare that they have no competing interests.

\section{Publisher's Note}

Springer Nature remains neutral with regard to jurisdictional claims in published maps and institutional affiliations.

Received: 30 January 2019 Accepted: 8 May 2019

Published online: 22 May 2019

References

1. Geszvain K, Butterfield C, Davis RE, Madison AS, Lee SW, Parker DL, Soldatova A, Spiro TG, Luther GW, Tebo BM. The molecular biogeochemistry of manganese (II) oxidation. Biochem Soc Trans. 2012;40(6):1244-8.

2. Sparrow LA, Uren NC. Manganese oxidation and reduction in soils: effects of temperature, water potential, pH and their interactions. Soil Res. 2014;52(5): 483-94.

3. Nagajyoti PC, Lee KD, Sreekanth TVM. Heavy metals, occurrence and toxicity for plants: a review. Environ Chem Lett. 2010;8(3):199-216.

4. Lucchini R, Placidi D, Cagna G, Fedrighi C, Oppini M, Peli M, Zoni S. Manganese and developmental neurotoxicity. Adv Neurobiol. 2017;18:13-34.

5. Millaleo R, Reyes-Díaz M, Ivanov AG, Mora ML, Alberdi M. Manganese as essential and toxic element for plants: transport, accumulation and resistance mechanism. J Soil Sci Plant Nutr. 2010;10(4):470-81.

6. Fernando DR, Lynch JP. Manganese phytotoxicity: new light on an old problem. Ann Bot. 2015;116(3):313-9.

7. González A, Steffen KL, Lynch JP. Light and excess manganese implications for oxidative stress in common bean. Plant Physiol. 1998;118(2):493-504

8. Führs H, Specht A, Erban A, Kopka J, Horst WJ. Functional associations between the metabolome and manganese tolerance in Vigna unguiculata. J Exp Bot. 2012;63(1):329-40

9. Millaleo R, Reyes-Diaz M, Alberdi M, Ivanov AG, Krol M, Huner NP. Excess manganese differentially inhibits photosystem I versus II in Arabidopsis thaliana. J Exp Bot. 2013;64(1):343-54.

10. Shi Q, Zhu Z. Effects of exogenous salicylic acid on manganese toxicity, element contents and antioxidative system in cucumber. Environ Exp Bot. 2008;63(1-3):317-26.

11. Sheng $H$, Zeng J, Liu $Y$, Wang $X$, Wang $Y$, Kang $H$, Fan $X$, Sha L, Zhang $H$, Zhou $Y$. Sulfur mediated alleviation of Mn toxicity in polish wheat relates to regulating $\mathrm{Mn}$ allocation and improving antioxidant system. Front Plant Sci. 2016;7:1382

12. Li Q, Chen LS, Jiang HX, Tang N, Yang LT, Lin ZH, Li Y, Yang GH. Effects of manganese-excess on $\mathrm{CO}_{2}$ assimilation, ribulose-1,5-bisphosphate carboxylase/oxygenase, carbohydrates and photosynthetic electron transport of leaves, and antioxidant systems of leaves and roots in Citrus grandis seedlings. BMC Plant Biol. 2010;10:42.

13. Ribera AE, Reyes-Diaz MM, Alberdi MR, Alvarez-Cortez DA, Rengel Z, de la Luz Mora M. Photosynthetic impairment caused by manganese toxicity and associated antioxidative responses in perennial ryegrass. Crop Pasture Sci. 2013;64(7):696-707.

14. Shao JF, Yamaji N, Shen RF, Ma JF. The key to Mn homeostasis in plants: regulation of Mn transporters. Trends Plant Sci. 2017;22(3):215-24.

15. Delhaize E, Kataoka T, Hebb DM, White RG, Ryan PR. Genes encoding proteins of the cation diffusion facilitator family that confer manganese tolerance. Plant Cell. 2003;15(5):1131-42. 
16. Fernando DR, Mizuno T, Woodrow IE, Baker AJ, Collins RN. Characterization of foliar manganese (Mn) in Mn (hyper) accumulators using X-ray absorption spectroscopy. New Phytol. 2010;188(4):1014-27.

17. Fecht-Christoffers MM, Führs H, Braun HP, Horst WJ. The role of hydrogen peroxide-producing and hydrogen peroxide-consuming peroxidases in the leaf apoplast of cowpea in manganese tolerance. Plant Physiol. 2006;140(4): 1451-63.

18. Delhaize E, Gruber BD, Pittman JK, White RG, Leung H, Miao Y, Jiang L, Ryan PR, Richardson AE. A role for the AtMTP11 gene of Arabidopsis in manganese transport and tolerance. Plant J. 2007;51(2):198-210.

19. Dragišic Maksimovic J, Mojovic M, Maksimovic V, Römheld V, Nikolic M. Silicon ameliorates manganese toxicity in cucumber by decreasing hydroxyl radical accumulation in the leaf apoplast. J Exp Bot. 2012;63(7):2411-20.

20. Eroglu S, Meier B, von Wirén N, Peiter E. The vacuolar manganese transporter MTP8 determines tolerance to iron deficiency-induced chlorosis in Arabidopsis. Plant Physiol. 2016;170(2):1030-45.

21. Takemoto Y, Tsunemitsu Y, Fujii-Kashino M, Mitani-Ueno N, Yamaji N, Ma JF, Kato SI, Iwasaki K, Ueno D. The tonoplast-localized transporter MTP8.2 contributes to manganese detoxification in the shoots and roots of Oryza sativa L. Plant Cell Physiol. 2017;58(9):1573-82.

22. Tsunemitsu Y, Genga M, Okada T, Yamaji N, Ma JF, Miyazaki A, Kato SI, Iwasaki K, Ueno D. A member of cation diffusion facilitator family, MTP11, is required for manganese tolerance and high fertility in rice. Planta. 2018; 248(1):231-41.

23. Rosas A, Rengel Z, de la Luz Mora M. Manganese supply and pH influence growth, carboxylate exudation and peroxidase activity of ryegrass and white clover. J Plant Nutr. 2007;30(2):253-70.

24. de la Luz Mora M, Rosas A, Ribera A, Rengel Z. Differential tolerance to $\mathrm{Mn}$ toxicity in perennial ryegrass genotypes: involvement of antioxidative enzymes and root exudation of carboxylates. Plant Soil. 2009;320(1-2):79-89.

25. Chen Z, Sun L, Liu P, Liu G, Tian J, Liao H. Malate synthesis and secretion mediated by a manganese-enhanced malate dehydrogenase confers superior manganese tolerance in Stylosanthes guianensis. Plant Physiol. 2015; 167(1):176-88.

26. Schultze-Kraft R, Rao IM, Peters M, Clements RJ, Bai C, Liu GD. Tropical forage legumes for environmental benefits: an overview. Trop Grassl Forrajes. 2018;6:1.

27. Andrew CS, Hegarty MP. Comparative responses to manganese excess of eight tropical and four temperate pasture legume species. Aust J Agvic Res. 1969;20(4):687-96.

28. Sun LL, Liang CY, Chen ZJ, Liu PD, Tian J, Liu GD, Liao H. Superior aluminium (Al) tolerance of Stylosanthes is achieved mainly by malate synthesis through an Al-enhanced malic enzyme, SgME1. New Phytol. 2014; 202(1):209-19.

29. Jiang C, Liu L, Li X, Han R, Wei Y, Yu Y. Insights into aluminum-tolerance pathways in Stylosanthes as revealed by RNA-Seq analysis. Sci Rep. 2018;8(1): 6072.

30. Metali F, Salim KA, Burslem DF. Evidence of foliar aluminium accumulation in local, regional and global datasets of wild plants. New Phytol. 2012; 193(3):637-49.

31. Tsunemitsu Y, Yamaji N, Ma JF, Kato SI, Iwasaki K, Ueno D. Rice reduces Mn uptake in response to Mn stress. Plant Signal Behav. 2018;13(1):e1422466.

32. Chen Z, Yan W, Sun L, Tian J, Liao H. Proteomic analysis reveals growth inhibition of soybean roots by manganese toxicity is associated with alteration of cell wall structure and lignification. J Proteome. 2016;143: $151-60$.

33. You X, Yang L, Lu Y, Li H, Zhang S, Chen L. Proteomic changes of Citrus roots in response to long-term manganese toxicity. Trees. 2014; 28(5):1383-99.

34. Führs H, Behrens C, Gallien S, Heintz D, Van Dorsselaer A, Braun HP, Horst WJ. Physiological and proteomic characterization of manganese sensitivity and tolerance in rice (Oryza sativa) in comparison with barley (Hordeum vulgare). Ann Bot. 2010;105(7):1129-40.

35. Lidon FC, Barreiro MG, Ramalho JC. Manganese accumulation in rice: implications for photosynthetic functioning. J Plant Physiol. 2004;161(11): 1235-44.

36. Sheng $H$, Zeng J, Yan F, Wang $X$, Wang $Y$, Kang $H$, Fan $X$, Sha L, Zhang $H$, Zhou $Y$. Effect of exogenous salicylic acid on manganese toxicity, mineral nutrients translocation and antioxidative system in polish wheat (Triticum polonicum L.). Acta Physiol Plant. 2015;37:32.
37. Feng JP, Shi QH, Wang XF. Effects of exogenous silicon on photosynthetic capacity and antioxidant enzyme activities in chloroplast of cucumber seedlings under excess manganese. Agri Sci China. 2009;8:40-50.

38. Cai W, Ma J, Chi W, Zou M, Guo J, Lu C, Zhang L. Cooperation of LPA3 and LPA2 is essential for photosystem II assembly in Arabidopsis. Plant Physiol. 2010;154(1):109-20.

39. Grieco M, Tikkanen M, Paakkarinen V, Kangasjarvi S, Aro EM. Steady-state phosphorylation of light-harvesting complex II proteins preserves photosystem I under fluctuating white light. Plant Physiol. 2012;160:1896910.

40. Kitao M, Lei T, Koike T. Effects of manganese toxicity on photosynthesis of white birch (Betula platyphylla var. japonica) seedlings. Physiol Plant. 1997; 101(2):249-56.

41. Schwarte S, Bauwe H. Identification of the photorespiratory 2phosphoglycolate phosphatase, PGLP1, in Arabidopsis. Plant Physiol. 2007; 144(3):1580-6.

42. Xu H, Zhang J, Zeng J, Jiang L, Liu E, Peng C, He Z, Peng X. Inducible antisense suppression of glycolate oxidase reveals its strong regulation over photosynthesis in rice. J Exp Bot. 2009;60(6):1799-809.

43. Moreno Jl, Martin R, Castresana C. Arabidopsis SHMT1, a serine hydroxymethyltransferase that functions in the photorespiratory pathway influences resistance to biotic and abiotic stress. Plant J. 2005;41(3):451-63.

44. Roth U, von Roepenack-Lahaye E, Clemens S. Proteome changes in Arabidopsis thaliana roots upon exposure to cd. J Exp Bot. 2006;57(15): 4003-13.

45. Sharma R, Sahoo A, Devendran R, Jain M. Over-expression of a rice tau class glutathione s-transferase gene improves tolerance to salinity and oxidative stresses in Arabidopsis. PLoS One. 2014;9(3):e92900.

46. Corrales I, Poschenrieder C, Barcelo J. Boron-induced amelioration of aluminium toxicity in a monocot and a dicot species. J Plant Physiol. 2008; 165(5):504-13.

47. Terol J, Soler $\mathrm{G}$, Talon M, Cercos $\mathrm{M}$. The aconitate hydratase family from Citrus. BMC Plant Biol. 2010;10:222.

48. Gerrard Wheeler MC, Arias CL, Maurino VG, Andreo CS, Drincovich MF. Identification of domains involved in the allosteric regulation of cytosolic Arabidopsis thaliana NADP-malic enzymes. FEBS J. 2009:276(19):5665-77.

49. Dou CM, Fu XP, Chen XC, Shi JY, Chen YX. Accumulation and detoxification of manganese in hyperaccumulator Phytolacca americana. Plant Biol. 2009; 11(5):664-70.

50. Kopittke PM, Lombi E, McKenna BA, Wang P, Donner E, Webb Rl, Blamey FP, de Jonge MD, Paterson D, Howard DL, et al. Distribution and speciation of $\mathrm{Mn}$ in hydrated roots of cowpea at levels inhibiting root growth. Physiol Plant. 2013;147(4):453-64.

51. Radadiya N, Parekh VB, Dobariya B, Mahatma L, Mahatma MK. Abiotic stresses alter expression of S-Adenosylmethionine synthetase gene, polyamines and antioxidant activity in pigeon pea (Cajanus cajan L) Legume Res 2016;39(6):905-913.

52. Ahsan N, Lee DG, Alam I, Kim PJ, Lee JJ, Ahn YO, Kwak SS, Lee IJ, Bahk JD, Kang KY, et al. Comparative proteomic study of arsenic-induced differentially expressed proteins in rice roots reveals glutathione plays a central role during as stress. Proteomics. 2008;8(17):3561-76.

53. Lei $Y$, Korpelainen H, Li C. Physiological and biochemical responses to high Mn concentrations in two contrasting Populus cathayana populations. Chemosphere. 2007;68(4):686-94.

54. Cochrane FC, Davin LB, Lewis NG. The Arabidopsis phenylalanine ammonia lyase gene family: kinetic characterization of the four PAL isoforms. Phytochemistry. 2004;65(11):1557-64.

55. Ralston L, Subramanian S, Matsuno M, Yu O. Partial reconstruction of flavonoid and isoflavonoid biosynthesis in yeast using soybean type I and type II chalcone isomerases. Plant Physiol. 2005;137(4):1375-88.

56. Nuoendagula X, Kamimura N, Mori T, Nakabayashi R, Tsuji Y, Hishiyama S, Saito K, Masai E, Kajita S. Expression and functional analyses of a putative phenylcoumaran benzylic ether reductase in Arabidopsis thaliana. Plant Cell Rep. 2016;35(3):513-26.

57. Pawlak-Sprada S, Arasimowicz-Jelonek M, Podgórska M, Deckert J. Activation of phenylpropanoid pathway in legume plants exposed to heavy metals. Part I. effects of cadmium and lead on phenylalanine ammonia-lyase gene expression, enzyme activity and lignin content. Acta Biochim Pol. 2011;58(2):211-6.

58. Dai LP, Dong XJ, Ma HH. Molecular mechanism for cadmium-induced anthocyanin accumulation in Azolla imbricata. Chemosphere. 2012;87(4): 319-25. 
59. Hu YL, Tan JL, Wang $C L$, Yang ZB, Yang $Y X$, Chen Z, Lin LJ, Wang YJ, Sun G, Zhu XM, et al. Research on root responses to Pb and Zn combined stress of Carex putuoshan. Protein Pept Lett. 2016;23(5):478-87.

60. Sheoran IS, Koonjul P, Attieh J, Saini HS. Water-stress-induced inhibition of a-tubulin gene expression during growth, and its implications for reproductive success in rice. Plant Physiol Biochem. 2014:80:291-9.

61. Han Y, Li A, Li F, Zhao M, Wang W. Characterization of a wheat (Triticum aestivum $\mathrm{L}$.) expansin gene, TaEXPB23, involved in the abiotic stress response and phytohormone regulation. Plant Physiol Biochem. 2012;54:49-58.

62. Rochange S, Wenzel C, McQueen-Mason S. Impaired growth in transgenic plants over-expressing an expansin isoform. Plant Mol Biol. 2001;46(5):581-9.

63. Shi YZ, Zhu XF, Miller JG, Gregson T, Zheng SJ, Fry SC. Distinct catalytic capacities of two aluminium-repressed Arabidopsis thaliana xyloglucan endotransglucosylase/hydrolases, XTH15 and XTH31, heterologously produced in Pichia. Phytochemistry. 2015;112:160-9.

64. Zhu XF, Shi YZ, Lei GJ, Fry SC, Zhang BC, Zhou YH, Braam J, Jiang T, Xu XY, Mao CZ, et al. XTH31, encoding an in vitro XEH/XET-active enzyme, regulates aluminum sensitivity by modulating in vivo XET action, cell wall xyloglucan content, and aluminum binding capacity in Arabidopsis. Plant Cell. 2012;24(11):4731-47.

65. Meier I, Brkljacic J. The nuclear pore and plant development. Curr Opin Plant Biol. 2009;12(1):87-95.

66. Wang $W$, Wang $Y$, Du Y, Zhao Z, Zhu X, Jiang X, Shu Z, Yin Y, Li X Overexpression of Camellia sinensis $\mathrm{H} 1$ histone gene confers abiotic stress tolerance in transgenic tobacco. Plant Cell Rep. 2014;33(11):1829-41.

67. Chamberlain JR, Lee Y, Lane WS, Engelke DR. Purification and characterization of the nuclear RNase P holoenzyme complex reveals extensive subunit overlap with RNase MRP. Genes Dev. 1998;12(11):1678-90.

68. Hanbauer I, Boja ES, Moskovitz J. A homologue of elongation factor 1 gamma regulates methionine sulfoxide reductase a gene expression in Saccharomyces cerevisiae. Proc Natl Acad Sci U S A. 2003;100(14):8199-204.

69. Visweswaraiah J, Lageix S, Castilho BA, Izotova L, Kinzy TG, Hinnebusch AG, Sattlegger E. Evidence that eukaryotic translation elongation factor $1 A$ (eEF1A) binds the Gcn2 protein C terminus and inhibits Gcn2 activity. J Biol Chem. 2011:286(42):36568-79.

70. Xu W, Jia L, Shi W, Baluska F, Kronzucker HJ, Liang J, Zhang J. The tomato 14-3-3 protein TFT4 modulates $\mathrm{H}^{+}$efflux, basipetal auxin transport, and the PKS5-J3 pathway in the root growth response to alkaline stress. Plant Physiol. 2013;163(4):1817-28.

71. Tran LS, Urao T, Qin F, Maruyama K, Kakimoto T, Shinozaki K, YamaguchiShinozaki K. Functional analysis of AHK1/ATHK1 and cytokinin receptor histidine kinases in response to abscisic acid, drought, and salt stress in Arabidopsis. Proc Natl Acad Sci U S A. 2007;104(51):20623-8.

72. Wohlbach DJ, Quirino BF, Sussman MR. Analysis of the Arabidopsis histidine kinase ATHK1 reveals a connection between vegetative osmotic stress sensing and seed maturation. Plant Cell. 2008;20(4):1101-17.

73. Qin Q, Wang W, Guo X, Yue J, Huang Y, Xu X, Li J, Hou S. Arabidopsis DELLA protein degradation is controlled by a type-one protein phosphatase, TOPP4. PLoS Genet. 2014;10(7):e1004464.

74. Tang Y, Wu Z, Liu G, Yi K. Research advances in germplasm resources of Stylosanthes. Chinese Bull Bot. 2009;44:752-62.

75. Kramer DM, Johnson G, Kirats O, Edwards GE. New fluorescence parameters for the determination of $\mathrm{Q}_{\mathrm{A}}$ redox state and excitation energy fluxes. Photosynth Res. 2004;79:209-18.

76. Pan L, Zhang X, Wang J, Ma X, Zhou M, Huang L, Nie G, Wang P, Yang Z, Li J. Transcriptional profiles of drought-related genes in modulating metabolic processes and antioxidant defenses in Lolium multiflorum. Front Plant Sci. 2016;7:519.

77. Bradford MM. A rapid and sensitive method for the quantitation of microgram quantities of protein utilizing the principle of protein-dye binding. Anal Biochem. 1976:72:248-54.

78. Vizcaíno JA, Csordas A, del-Toro N, Dianes JA, Griss J, Lavidas I, Mayer G, Perez-Riverol Y, Reisinger F, Ternent T, et al. 2016 update of the PRIDE database and its related tools. Nucleic Acids Res. 2016:44(22):11033.

\section{Ready to submit your research? Choose BMC and benefit from:}

- fast, convenient online submission

- thorough peer review by experienced researchers in your field

- rapid publication on acceptance

- support for research data, including large and complex data types

- gold Open Access which fosters wider collaboration and increased citations

- maximum visibility for your research: over $100 \mathrm{M}$ website views per year

At BMC, research is always in progress.

Learn more biomedcentral.com/submissions 